\title{
LX2761, a Sodium/Glucose Cotransporter 1 Inhibitor Restricted to the Intestine, Improves Glycemic Control in Mice ${ }^{\mathrm{S}}$
}

\author{
David R. Powell, Melinda G. Smith, Deon D. Doree, Angela L. Harris, Jennifer Greer, \\ Christopher M. DaCosta, Andrea Thompson, Sabrina Jeter-Jones, Wendy Xiong, \\ Kenneth G. Carson, Nicole C. Goodwin, Bryce A. Harrison, David B. Rawlins, \\ Eric D. Strobel, Suma Gopinathan, Alan Wilson, Faika Mseeh, Brian Zambrowicz, \\ and Zhi-Ming Ding
}

Lexicon Pharmaceuticals, Inc., The Woodlands, Texas

Received February 17, 2017; accepted April 20, 2017

\begin{abstract}
LX2761 is a potent sodium/glucose cotransporter 1 inhibitor restricted to the intestinal lumen after oral administration. Studies presented here evaluated the effect of orally administered LX2761 on glycemic control in preclinical models. In healthy mice and rats treated with LX2761, blood glucose excursions were lower and plasma total glucagon-like peptide-1 (GLP-1) levels higher after an oral glucose challenge; these decreased glucose excursions persisted even when the glucose challenge occurred 15 hours after LX2761 dosing in ad lib-fed mice. Further, treating mice with LX2761 and the dipeptidyl-peptidase 4 inhibitor sitagliptin synergistically increased active GLP-1 levels, suggesting increased LX2761-mediated release of GLP-1 into the portal circulation. LX2761 also lowered postprandial glucose, fasting glucose, and hemoglobin A1C, and increased plasma total GLP-1, during long-term treatment of mice with either early- or late-onset
\end{abstract}

streptozotocin-diabetes; in the late-onset cohort, LX2761 treatment improved survival. Mice and rats treated with LX2761 occasionally had diarrhea; this dose-dependent side effect decreased in severity and frequency over time, and LX2761 doses were identified that decreased postprandial glucose excursions without causing diarrhea. Further, the frequency of LX2761-associated diarrhea was greatly decreased in mice either by gradual dose escalation or by pretreatment with resistant starch 4, which is slowly digested to glucose in the colon, a process that primes the colon for glucose metabolism by selecting for glucose-fermenting bacterial species. These data suggest that clinical trials are warranted to determine if LX2761 doses and dosing strategies exist that provide improved glycemic control combined with adequate gastrointestinal tolerability in people living with diabetes.

\section{Introduction}

Diabetes is a major public health problem with increasing morbidity and mortality worldwide (Centers for Disease Control and Prevention, 2014; Danaei et al., 2014; Zhou et al., 2016). Individuals with diabetes are at risk for microvascular and cardiovascular complications which may be avoided or minimized with improved glycemic control (Inzucchi et al., 2015; Zhou et al., 2016). Approximately $90-95 \%$ of these individuals have type 2 diabetes (T2D), characterized by hyperglycemia secondary to peripheral insulin resistance and relative insulin deficiency from progressive beta cell failure (DeFronzo, 2009; Centers for Disease Control and Prevention, 2014; Danaei et al., 2014). Although many medications are approved for use in individuals with T2D, treatment

https://doi.org/10.1124/jpet.117.240820.

S This article has supplemental material available at jpet.aspetjournals.org. with these medications often fails to achieve a hemoglobin A1C (A1C) < 7\% (Esposito et al., 2012), suggesting the need for additional treatments that improve glycemic control. The remaining $5-10 \%$ of diabetic patients have type 1 diabetes (T1D), characterized by autoimmune destruction of beta cells that gradually results in absolute insulin deficiency (Bluestone et al., 2010; Centers for Disease Control and Prevention, 2014; Danaei et al., 2014). In these individuals, aggressive use of insulin to optimize glycemic control often results in obesity (Wajchenberg et al., 2008) and episodes of severe hypoglycemia (Cengiz et al., 2013; Weinstock et al., 2013), which emphasizes the need to develop adjunct therapies to insulin that both improve glycemic control and decrease severity of these comorbidities.

Sodium/glucose cotransporter 2 (SGLT2) inhibitors are a new class of antidiabetic therapeutics (Mudaliar et al., 2015). These orally available small molecules act by inhibiting SGLT2 in the kidney, which decreases glucose reabsorption

ABBREVIATIONS: A1C, hemoglobin A1C; AMG, $\alpha$-methylglucopyranoside; AUC, area under the curve; DPP4, dipeptidyl-peptidase 4; aGLP-1, active glucagon-like peptide-1; GSK-1614235, 3-((3-(4-((5-isopropyl-3-(((2S,3R,4S,5S,6R)-3,4,5-trihydroxy-6-(hydroxymethyl)tetrahydro-2H-pyran2-yl)oxy)-1H-pyrazol-4-yl)methyl)-3-methylphenoxy)propyl)amino)-2,2-dimethylpropanamide; HEK, human embryonic kidney; HGD, high-glucose diet; OGTT, oral glucose tolerance test; KGA-2727, 3-(3-\{4-[3-( $\beta$-D-glucopyranosyloxy)-5-isopropyl-1H-pyrazol-4-ylmethyl]-3-methylphenoxy\} propylamino)propionamide; RS4, resistant starch 4; SCFA, short-chain fatty acid; SGLT, sodium/glucose cotransporter; STZ, streptozotocin; T2D, type 2 diabetes; tGLP-1, total glucagon-like peptide-1; UGE, urinary glucose excretion. 
in the proximal tubule; the resulting increase in urinary glucose excretion (UGE) improves glycemic control in individuals with diabetes (Wright et al., 2011; Mudaliar et al., 2015). Most of these compounds were developed to selectively inhibit SGLT2 over the closely related transporter SGLT1 owing to concern for intestinal side effects, because it is SGLT1, not SGLT2, that is expressed in intestine and is responsible for intestinal glucose absorption, and individuals lacking functional SGLT1 exhibit an intestinal malabsorption syndrome, designated glucose galactose malabsorption (OMIM182380), when they ingest normal dietary amounts of these sugars (Wright et al., 2011; Mudaliar et al., 2015). Sotagliflozin is a less selective SGLT2 inhibitor than other family members, with an $\mathrm{IC}_{50}$ of $1.8 \mathrm{nM}$ for SGLT2 and $36 \mathrm{nM}$ for SGLT1 (Zambrowicz et al., 2012; Mudaliar et al., 2015). Sotagliflozin improves glycemic control in mice and humans with T1D and T2D, in part by inhibiting renal SGLT2 to increase UGE but also by lowering blood glucose excursions, delaying peak blood glucose levels, and increasing circulating levels of total glucagon-like peptide-1 (tGLP-1) and peptide YY after oral glucose challenge (Zambrowicz et al., 2012, 2013, 2015; Powell et al., 2014, 2015; Rosenstock et al., 2015; Sands et al., 2015); these latter effects are consistent with inhibition of SGLT-1mediated intestinal glucose absorption (Powell et al., 2013a, b). This apparent inhibition of intestinal SGLT1 by sotagliflozin was not associated with intestinal side effects, suggesting that a therapeutic window exists where partial inhibition of intestinal SGLT1 can improve glycemic control without being accompanied by diarrhea, cramps, or other symptoms of glucose malabsorption.

We are developing LX2761, a compound restricted to the intestinal lumen where it inhibits SGLT1, to provide a therapeutic option for people with diabetes that improves their glycemic control with minimal systemic side effects and adequate gastrointestinal tolerability. In our initial report (Goodwin et al., 2017), we showed that LX2761 inhibits SGLT1 and SGLT2 with IC $_{50}$ values of 2.2 and $2.7 \mathrm{nM}$, respectively. Consistent with being designed to have poor oral bioavailability, LX2761 had extremely low systemic exposure after oral administration to healthy mice and was unable to appreciably increase UGE by inhibiting renal SGLT2; in contrast, sotagliflozin administered orally to healthy mice at the same dose had excellent systemic exposure and markedly increased UGE. Despite poor systemic exposure, LX2761 delivered orally to healthy mice before an oral glucose challenge resulted in lower postprandial glucose excursions, higher plasma tGLP-1 and cecal glucose levels, and lower cecal pH, all consistent with local inhibition of intestinal SGLT1 by LX2761. The present manuscript explores the effect of LX2761 on various parameters related to glycemic control in rats, diabetic mice, and mice treated with the dipeptidyl-peptidase 4 (DPP4) inhibitor sitagliptin, characterizes the effect of different LX2761 doses on postprandial glucose excursions and on the side effect of diarrhea, and explores the ability of dose escalation and pretreatment with resistant starch 4 (RS4) to minimize diarrhea in LX2761-treated mice.

\section{Materials and Methods}

Mice and Rats. All studies were performed at Lexicon Pharmaceuticals, Inc., in strict accordance with the recommendations in the Guide for the Care and Use of Laboratory Animals of the National
Institutes of Health. The protocols for all studies were approved by the Lexicon Institutional Animal Care and Use Committee (OLAW Assurance Number A4152-01; AAALAC International Accreditation Number 001025). General methods for mouse and rat care have been described (Powell et al., 2013a, 2014). C57BL/6-Tyrc-Brd mice obtained from an in-house colony were fed either standard rodent chow diet (5010, LabDiet; PMI Nutrition International, St. Louis, MO), high-glucose diet (HGD; D12451; Research Diets, New Brunswick, NJ) with a kcal distribution of $20 \%$ from protein $/ 10 \%$ from lard fat $/ 35 \%$ from sucrose $/ 35 \%$ from standard starch, HGD containing resistant starch 4 (HGD-RS4; D13072202; Research Diets) with a kcal distribution of $31 \%$ from protein $/ 16 \%$ from lard fat $/ 35 \%$ from sucrose $/ 11 \%$ from standard starch/7\% from RS4 (Fibersym RW, MGP, Inc., Atchison, KS), or HGD containing resistant starch 2 (HGD-RS2; D13072201; Research Diets) with a kcal distribution of $25 \%$ from protein $/ 13 \%$ from lard fat $/ 35 \%$ from sucrose $/ 9 \%$ from standard starch/18\% from RS2 (H-Maize 260; Honeyville, Inc., Salt Lake City, UT). Crl:CD Sprague-Dawley Rats (Charles River Laboratories International, Wilmington, MA) were obtained at 4 weeks of age and fed either chow or HGD. For all in vivo studies, mice and rats were fed HGD because glucose must be a major source of dietary calories if the effects of SGLT1 inhibition on glucose homeostasis are to be evaluated. All mice and rats were maintained in a temperature-controlled environment on a fixed 12 hour light/12 hour dark cycle and with free access to water and food. For each study: 1) mice or rats in each study group were taken from the same animal cohort and housed in the same room under comparable conditions; 2) mice and rats were randomly assigned a number that had no relation to body weight; and 3) mice and rats were randomized to individual study groups by body weight unless stated otherwise.

LX2761, LP-945013, and Sotagliflozin. LX2761, $N-(1-((2-$ (dimethylamino)ethyl)amino)-2-methyl-1-oxopropan-2-yl)-4-(4-(2methyl-5-((2S,3R,4R,5S,6R)-3,4,5-trihydroxy-6-(methylthio)tetrahydro$2 \mathrm{H}$-pyran-2-yl)benzyl)phenyl)butanamide; LP-945013, $(2 S, 3 R, 4 R, 5 S, 6 R)$ 2-(3-(4-(3-((1-hydroxy-2-methylpropan-2-yl)amino)propoxy)benzyl)4-methylphenyl)-6-(methylthio)tetrahydro-2H-pyran-3,4,5-triol; and sotagliflozin were synthesized at Lexicon Pharmaceuticals (Goodwin et al., 2008; Zambrowicz et al., 2012; Carson et al., 2014; Goodwin et al., 2017); LP-945013 has also been referred to as compound 7 (Goodwin et al., 2017). In all in vivo studies presented here, LX2761, LP-945013, and sotagliflozin were administered by oral gavage in a volume of no more than $10 \mathrm{ml} / \mathrm{kg}$, and the vehicle was always aqueous $0.1 \% \mathrm{v} / \mathrm{v}$ Tween 80 .

Measurement of 24-Hour UGE. At 20 weeks of age, male mice were individually housed in metabolic cages (Nalge Nunc International, Rochester, NY) and fed powdered HGD homogenized in water at a $2: 1(\mathrm{wt} / \mathrm{wt})$ ratio; this paste diet prevented contamination of urine with crumbled diet. After an acclimatization period, each mouse received, by oral gavage, a single dose of either vehicle or vehicle containing $1.5 \mathrm{mg} / \mathrm{kg}$ of LP-945013. Complete 24-hour urine samples were collected during the 24 hours after dosing (day 1 ) and also on days 2 and 3. After the volume of each 24-hour urine collection was recorded, the urine sample was centrifuged and analyzed for glucose concentration (Cobas Integra 400 Clinical Chemistry Autoanalyzer; Roche Diagnostics, Indianapolis, IN).

Analysis of Blood Samples. Whole-blood glucose was measured using an Accu-Chek Aviva glucometer (Roche Diagnostics). A1C was measured using an assay kit (A1C Now + System; Bayer HealthCare, Tarrytown, NY) according to the manufacturer's instructions, as described previously (Powell et al., 2014). Levels of tGLP-1 were measured using the GLP-1 Total ELISA Kit (cat. no. EZGLP1T-36K; Millipore, St. Charles, MO), and levels of active GLP-1 (aGLP-1) were measured using the Glucagon-Like Peptide-1 Active ELISA Kit (cat. no. EGLP-35K; Millipore) exactly as described previously (Powell et al., 2013b).

Oral Glucose Tolerance Tests. Oral glucose tolerance tests (OGTTs) were performed on unanesthetized adult male mice and rats. Mice: after predose blood samples were collected from the retro-orbital 
plexus at baseline, each mouse received, by oral gavage, 4 g glucose $/ \mathrm{kg}$ body weight. Retro-orbital blood samples were then collected at multiple subsequent time points and assayed for whole-blood glucose. Rats: After predose blood samples were collected from the saphenous vein at baseline, each rat received, by oral gavage, $4 \mathrm{~g}$ glucose $/ \mathrm{kg}$ body weight. Saphenous blood samples were then collected at 10,30,60, and 120 minutes after glucose challenge and assayed for whole-blood glucose.

Glucose-Containing Meal Challenge. Adult male mice fed HGD for 6 days prior to study were randomized into two treatment groups. Vehicle or LX2761 was administered by oral gavage at 8:00 $\mathrm{AM}$ once daily for 4 consecutive days; body weight and food consumption were measured daily. On day 4, a meal consisting of HGD supplemented with glucose was prepared by adding $50 \mathrm{~g}$ of HGD powder and $9.4 \mathrm{~g}$ of glucose to $\mathrm{H}_{2} \mathrm{O}$; the final volume was $94 \mathrm{ml}$, as described previously (Powell et al., 2013b). The meal was prepared and kept at $60^{\circ} \mathrm{C}$ until used. At 6 hours after the last dose of LX2761, the mice received $25 \mathrm{ml} / \mathrm{kg}$ of this meal $(9.2 \mathrm{~g} / \mathrm{kg}$ glucose, $2.5 \mathrm{~g} / \mathrm{kg}$ protein, $0.6 \mathrm{~g} / \mathrm{kg}$ fat) by oral gavage. Blood samples were collected by retro-orbital bleeding at $0,10,30$, and 60 minutes after meal challenge for assessment of glucose excursion. In addition, blood samples collected 60 minutes after meal challenge were used to measure circulating levels of tGLP-1 as described previously (Powell et al., $2013 \mathrm{~b}$ ). Mice were necropsied at the end of the meal challenge ( 7 hours after the last dose of LX2761) and their cecal contents were collected and analyzed for $\mathrm{pH}$ and total glucose as described previously (Powell et al., 2013b).

Analysis of Stool Consistency. Preliminary studies showed that the presence of normal bedding interfered with the ability to characterize stool consistency. Therefore, in studies where stool consistency was formally evaluated, mice or rats were individually placed in microisolator cages with wire-grid flooring. Stool consistency was graded daily using the following scoring system: $0=$ normal size/dry stools; $1=$ swollen/enlarged/wet stools in normal shape; $2=$ unformed/ not wet stools OR formed/wet stools (yellowish wet ring around stools when placed on paper towel); $3=$ unformed/wet stools (wet anus fur; yellowish wet ring around stools when placed on paper towel). Scores of 2 and 3 were considered episodes of frank diarrhea.

LX2761 Dose Escalation and Resistant Starch Pretreatment Studies. Dose escalation: Individually housed male mice were fed HGD for 1 week before being randomized into four groups. On day 1 (the first day of LX2761 treatment), group 1 mice received LX2761 at $0.05 \mathrm{mg} / \mathrm{kg}$ by oral gavage at 5:00 PM once daily for 4 days. The dose for the mice in group 1 then increased by $0.05 \mathrm{mg} / \mathrm{kg}$ every 4 days through day 24 . After day 24 , the dose for mice in group 1 increased $0.05 \mathrm{mg} / \mathrm{kg}$ every 7 days. On days 45,52 , and 59, the mice in group 1 had their LX2761 dose raised to $0.5,0.6$, and $0.7 \mathrm{mg} / \mathrm{kg}$, respectively. Mice in groups 2,3 , and 4 served as controls for the mice in group 1 by receiving a 7-day LX2761 challenge at doses of $0.5,0.6$, or $0.7 \mathrm{mg} / \mathrm{kg}$ starting on days 45,52 , and 59 , respectively. All mice receiving LX2761 doses of $0.5,0.6$, or $0.7 \mathrm{mg} / \mathrm{kg}$ were assessed daily for stool consistency according to the scoring system outlined above.

Resistant starch pretreatment: After individually housed male mice were fed either HGD, HGD-RS2, or HGD-RS4 for 21 days, they were provided only HGD for the remainder of the study, and randomized to receive either vehicle, LX2761, or LP-945013 by oral gavage once daily at 5:00 PM for 3 or 4 consecutive days. Stool consistency was assessed daily during RS2 or RS4 pretreatment and also during subsequent compound treatment. The effect of RS4 pretreatment on LX2761mediated changes in OGTT glucose excursions and cecal glucose and $\mathrm{pH}$ levels was analyzed in a separate study.

LX2761 and Sitagliptin Combination Studies. Single-dose study: HGD-fed adult mice were randomized into four groups. A single dose of either vehicle, LX2761 $(0.15 \mathrm{mg} / \mathrm{kg})$, the DPP4 inhibitor sitagliptin $(30 \mathrm{mg} / \mathrm{kg})$, or the combination of LX2761 $(0.15 \mathrm{mg} / \mathrm{kg})$ and sitagliptin $(30 \mathrm{mg} / \mathrm{kg})$ was administered to the mice by oral gavage. At 30 minutes after compound/vehicle dosing, mice received glucose water $(4 \mathrm{~g} / \mathrm{kg}, 10 \mathrm{ml} / \mathrm{kg})$ by oral gavage. At different time points after glucose administration, blood samples were obtained by retroorbital bleeding for measurement of aGLP-1 levels.

Multiple-dose study: This was performed exactly as was the singledose study with the exception that the mice received either vehicle, LX2761, sitagliptin, or the LX2761/sitagliptin combination by oral gavage once daily for 14 days prior to the glucose challenge.

LX2761 Treatment of Mice with Streptozotocin-Induced Diabetes. HGD-fed, adult male mice received $40 \mathrm{mg} / \mathrm{kg}$ of streptozotocin (STZ; 50 mM sodium citrate, $\mathrm{pH} 4.5$ ) via intraperitoneal injection for 5 consecutive days.

Effect in mice with early diabetes: 1 week after the last STZ injection, each mouse had baseline A1C and fed-glucose levels measured, and only mice with fed-glucose levels $>200 \mathrm{mg} / \mathrm{dl}$ were considered diabetic; they were immediately randomized into three groups on the basis of their baseline fed-glucose level and body weight. They received either vehicle $(0.1 \%$ Tween 80 in water) or LX2761 at a dose of either 1.5 or $3 \mathrm{mg} / \mathrm{kg}$ once daily by oral gavage for 39 consecutive days; dosing was at 5:00 PM with the exception of treatment days 21 and 39, when dosing occurred at 7:00 AM. During the study, A1C and fasting glucose levels were obtained on day 32,15 hours after the last LX2761 dose. In addition, two OGTTs were performed, on treatment days 21 and 39, in fed mice 6 hours after the last LX2761 dose. Blood collected 2 hours after the OGTT glucose challenge on treatment day 39 was also used to measure circulating levels of tGLP-1. Mice were necropsied 2 hours after the glucose challenge ( 8 hours after the last dose of LX2761) on treatment day 39 , and cecal contents were collected and analyzed for $\mathrm{pH}$ and total glucose.

Effect in mice with advanced diabetes: One week after the last STZ dose, each mouse underwent an OGTT in the fed state, and only mice with blood glucose $>300 \mathrm{mg} / \mathrm{dl}$ measured 30 minutes after glucose challenge were studied further. They were re-evaluated with baseline A1C levels 47 days after the last STZ dose, and only those mice with A1C levels $>5.7 \%$ were considered diabetic. On day 65 after the last STZ dose, diabetic mice were randomized into three groups on the basis of their baseline $\mathrm{A} 1 \mathrm{C}$ and body weight. They then received either vehicle or LX2761 at a dose of 1.5 or $3 \mathrm{mg} / \mathrm{kg}$ once daily by oral gavage for 49 consecutive days; dosing was at 5:00 PM with the exception of treatment day 49, when dosing occurred at 7:00 AM. During the course of treatment, A1C was measured on treatment day 30, and OGTTs were performed twice: on treatment day 20 in fed mice 15 hours after the last LX2761 dose and on treatment day 49 in fasted mice 6 hours after the last LX2761 dose. Blood collected 2 hours after the OGTT glucose challenge on treatment day 49 was also used to measure circulating levels of tGLP-1. Mice were necropsied 2 hours after the glucose challenge ( 8 hours after the last dose of LX2761) on treatment day 49 , and cecal contents were collected and analyzed for $\mathrm{pH}$ and total glucose.

Pharmacokinetics. Adult male rats (350-450 g) and mice (25$35 \mathrm{~g}$ ) were maintained on chow diet with free access to water and were conscious throughout the study. For bolus intravenous administration (IV), LX2761 or sotagliflozin was dissolved in $0.1 \%$ Tween 80 to form a clear solution and administered at a dose of $1 \mathrm{mg} / \mathrm{kg}$. For oral administration, LX2761 or sotagliflozin was provided by gavage to rats at a dose of $50 \mathrm{mg} / \mathrm{kg}$, and LP-945013 was provided by gavage to mice at doses of 10 or $30 \mathrm{mg} / \mathrm{kg}$. Following intravenous injection, serial blood samples were collected in EDTA-containing tubes through 6 hours, and following oral administration, serial blood samples were collected through 24 hours. The plasma fraction was immediately separated by centrifugation at $4^{\circ} \mathrm{C}$, and then stored at $-20^{\circ} \mathrm{C}$ until sample analysis. Bioanalysis of plasma samples for quantitating plasma LX2761, LP-945013, and sotagliflozin concentrations was conducted using liquid chromatography-mass spectroscopy.

Pharmacokinetic Data Analysis. All plasma concentrationversus-time data for LX2761 and LP-945013 were analyzed using noncompartmental model 200 (for oral administration) and 201 (for IV administration) of WinNonlin (version 5.0; Pharsight, Inc. Mountain View, CA) as described previously (Powell et al., 2014). The half-life during the terminal phase was calculated from the elimination rate 
constant $(\lambda)$ determined by the linear regression analysis of the loglinear part of the plasma concentration curve. The area under the plasma concentration-time curve from time zero to time $t\left(\mathrm{AUC}_{0-\mathrm{t}}\right)$ was calculated using linear up/log down trapezoidal method up to the last measured concentration at time $\mathrm{t}\left(\mathrm{C}_{\mathrm{t}}\right)$. The area under the plasma concentration-time curve from time zero to time infinity $\left(\mathrm{AUC}_{0-\infty}\right)$ was calculated as $\mathrm{AUC}_{0-\mathrm{t}}+\mathrm{C}_{t} / \lambda$. Clearance (CL) was calculated by dose/AUC ${ }_{0-\infty}$. Other pharmacokinetic parameters included plasma peak concentration $\left(\mathrm{C}_{\max }\right)$, the time of $\mathrm{C}_{\max }\left(\mathrm{T}_{\max }\right)$, and volume of distribution at steady state $\left(\mathrm{V}_{\mathrm{ss}}\right)$.

Plasma Protein Binding. Plasma protein binding was determined by equilibrium dialysis assay using the Spectra/Por Equilibrium Dialyzer with micro Teflon cells (Spectrum Laboratories, Rancho Dominguez, CA) and Spectra/Por 2, precut 33-mm diameter membrane discs with a 12 - to $14-\mathrm{K}$ molecular weight cut-off (Spectrum Laboratories).

$\boldsymbol{\alpha}$-Methylglucopyranoside Uptake Assay. The development of human embryonic kidney (HEK) 293 cell lines expressing SGLT1 or SGLT2 from multiple species has been described previously (Zambrowicz et al., 2012; Powell et al., 2013b, 2014). When expressed in cells, SGLT2 and SGLT1 mediate sodium-coupled uptake of Dglucose or $\alpha$-methylglucopyranoside (AMG), a nonmetabolizable glucose analog specific for sodium-dependent glucose transporters. The ability of LX2761, and sotagliflozin as a comparator, to inhibit SGLT1and SGLT2-mediated glucose transport was estimated by measuring SGLT1- or SGLT2-mediated ${ }^{14} \mathrm{C}$-AMG uptake in the presence of increasing compound concentration, and determining the $\mathrm{IC}_{50}$ (concentration causing half-maximal inhibition), as described previously (Zambrowicz et al., 2012; Powell et al., 2013b, 2014).

Compound Washout Study. HEK293 cells expressing human SGLT1 or human SGLT2 were incubated with $1 \mu \mathrm{M}$ compound at $37^{\circ} \mathrm{C}$ for 30 minutes in uptake buffer $(140 \mathrm{mM} \mathrm{NaCl}, 2 \mathrm{mM} \mathrm{KCl}, 1 \mathrm{mM}$ $\mathrm{CaCl}_{2}, 1 \mathrm{mM} \mathrm{MgCl} 2,10 \mathrm{mM}$ HEPES, $5 \mathrm{mM}$ Tris, $1 \mathrm{mg} / \mathrm{ml}$ bovine serum albumin, $\mathrm{pH}$ 7.3). Cells were then washed followed by incubation in medium containing $25 \mathrm{mM}$ glucose; after 21 hours, cells were rewashed and ${ }^{14} \mathrm{C}-\mathrm{AMG}$ uptake was measured. To generate control data, HEK293 cells expressing human SGLT1 or human SGLT2 were incubated in the absence of compound at $37^{\circ} \mathrm{C}$ for 30 minutes in uptake buffer. Cells were then washed followed by incubation in medium containing $25 \mathrm{mM}$ glucose; after 21 hours, cells were rewashed and ${ }^{14} \mathrm{C}$-AMG uptake was then measured in the presence of $1 \mu \mathrm{M}$ compound.

Lactobacillus Acidophilus Studies. Individually housed male mice were fed HGD for 7 days before each study.

LX2761 effect on L. acidophilus abundance: Mice were randomized into two groups by body weight to receive either vehicle or LX2761 at a daily dose of $0.5 \mathrm{mg} / \mathrm{kg}$. After 14 days, mice were euthanized. Cecums were tied at both ends using surgical suture, excised, and then sealed in sterile tubes. Samples were kept on wet ice until cecal contents were cultured on tryptose blood agar plates for $L$. acidophilus quantification.

L. acidophilus pretreatment: Mice were randomized into treatment groups by body weight. A 10-mg tablet of Probiotic Gold (Nature's Bounty, Bohemia, NY) containing 1 billion colony-forming units of $L$. acidophilus was formulated in cold water $(0.3 \mathrm{mg} / \mathrm{ml})$. Mice received either the formulated Probiotic Gold $(10 \mathrm{ml} / \mathrm{kg}$ ) or vehicle (water) by oral gavage once daily for 11 days. On day 8, these mice also began to receive either vehicle or LX2761 once daily for the final 4 days. Stool consistency was assessed daily during the final 4 study days.

Statistics. Data are presented as mean \pm S.D. unless stated otherwise. Blood glucose time-course data converted to area-underthe-curve (AUC) values by trapezoidal summation, fasting blood glucose levels, A1C levels, total cecal glucose, cecal pH, tGLP1 levels, food consumption, and change in body weight were analyzed by oneway analysis of variance (ANOVA) with post-hoc analysis performed by the Bonferroni method. For the LX2761/sitagliptin combination studies, aGLP-1 time-course data were converted to AUC values by trapezoidal summation and then analyzed by two-way ANOVA. For studies involving the effect of LX2761 dose escalation or the effect of $\mathrm{RS} 2$ or RS4 pretreatment prior to compound dosing on the prevalence of diarrhea, comparisons between two groups were analyzed by the Mann-Whitney test and comparisons among three groups were analyzed by the Kruskal-Wallace test with post-hoc analysis performed by Dunn's multiple comparison test. For studies of LX2761 treatment in mice with STZ-induced diabetes, survival curves created using the product limit method of Kaplan and Meier were compared by the log-rank test with post-hoc analysis performed by the Bonferroni method. All statistical analyses were performed using PRISM 4.03 (GraphPad, La Jolla, CA) software. Values were considered statistically significant when $P<0.05$.

\section{Results}

The structure of LX2761, chemical name $N$-(1-((2(dimethylamino)ethyl)amino)-2-methyl-1-oxopropan-2-yl)-4(4-(2-methyl-5-((2S,3R,4R,5S,6R)-3,4,5-trihydroxy-6-(methylthio)tetrahydro-2H-pyran-2-yl)benzyl)phenyl)butanamide, is presented in Fig. 1A. As shown in Table 1, LX2761 potently inhibited human SGLT1- and SGLT2-mediated glucose uptake with $\mathrm{IC}_{50}$ values of $2.2 \pm 0.7 \mathrm{nM}$ and $2.7 \pm 0.8 \mathrm{nM}$, respectively (Goodwin et al., 2017). In addition, LX2761 was a potent inhibitor of mouse, rat, dog, and monkey SGLT1 and SGLT2 in vitro. The major pharmacokinetic parameters of LX2761 after intravenous or oral administration to rats are shown in Tables 2 and 3, respectively. The plasma concentration-time profile after rats received an oral $50 \mathrm{mg} / \mathrm{kg}$ dose is presented in Fig. 1B; data resulting from the same dose of sotagliflozin in rats are provided for comparison. Following an intravenous $1-\mathrm{mg} / \mathrm{kg}$ dose, the clearance of LX2761 was higher $(49.1 \mathrm{ml} / \mathrm{min}$ per kilogram) than that of sotagliflozin $(21.3 \mathrm{ml} / \mathrm{min}$ per kilogram). Following an oral $50 \mathrm{mg} / \mathrm{kg}$ dose, LX2761 had a $\mathrm{T}_{\max }$ of 0.6 hours, $\mathrm{C}_{\max }$ of $37 \mathrm{nM}$, and $\mathrm{AUC}_{0-\text { last }}$ of $424 \mathrm{nM}^{*} \mathrm{hr}$, with large variability in plasma levels, including plasma levels that were below the limit of quantitation $(7.7 \mathrm{ng} / \mathrm{ml})$ at the 6 -hour and 24-hour time points; in contrast, sotagliflozin had a $\mathrm{T}_{\max }$ of 1.9 hours, $\mathrm{C}_{\max }$ of $11,918 \mathrm{nM}$, and $\mathrm{AUC}_{0-\text { last }}$ of $52,027 \mathrm{nM} \mathrm{nM}^{*} \mathrm{hr}$ with an average terminal half-life of 2.4 hours. Thus, the exposure of orally administered LX2761 was significantly lower than that of sotagliflozin, reflecting the very low oral bioavailability $(<5 \%)$ of LX2761; these data are similar to LX2761 pharmacokinetic data generated in mice (Goodwin et al., 2017). LX2761 exhibited moderate binding to rat plasma proteins ( $72.4 \%$ bound) and mouse plasma proteins (77\% bound); in comparison, sotagliflozin exhibited high binding to both rat and mouse plasma proteins (97.7\% bound in each species).

Further studies employed an in vitro compound washout assay in an attempt to assess the effective residence time of LX2761, compared with that of sotagliflozin and phlorizin, on SGLT1 (Fig. 1C) and SGLT2 (Fig. 1D). LX2761 was similar to sotagliflozin in being resistant to washout from cells expressing either SGLT1 or SGLT2; thus, SGLT1- or SGLT2expressing cells incubated with either LX2761 or sotagliflozin were unable to efficiently transport labeled glucose despite washing. In contrast, phlorizin was readily washed from cells expressing either SGLT1 or SGLT2; thus, SGLT1- or SGLT2expressing cells incubated with phlorizin were able to efficiently transport labeled glucose after a similar washing.

To determine the effects of LX2761-mediated inhibition of SGLT1-mediated glucose uptake in the intestine, male mice that had received either LX2761 or vehicle by oral gavage for 
A<smiles>Cc1ccc(Cc2ccc(CCCC(=O)NC(C)(C)C(=O)NCCN(C)C)cc2)cc1C1O[C@H](C)[C@H](O)[C@H](O)[C@H]1O</smiles>

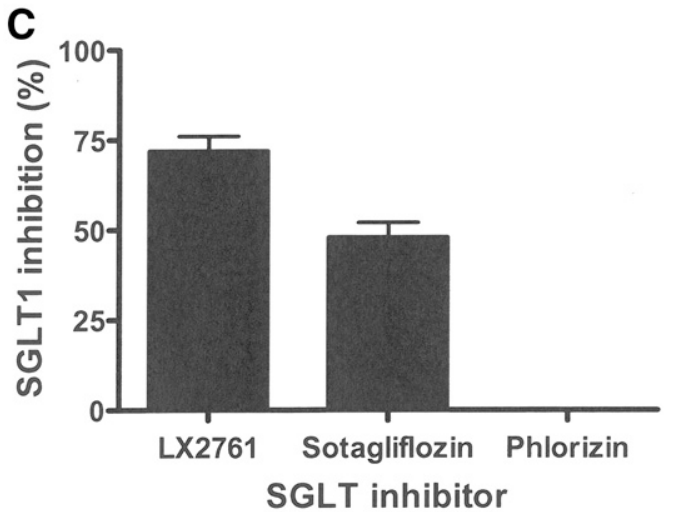

B
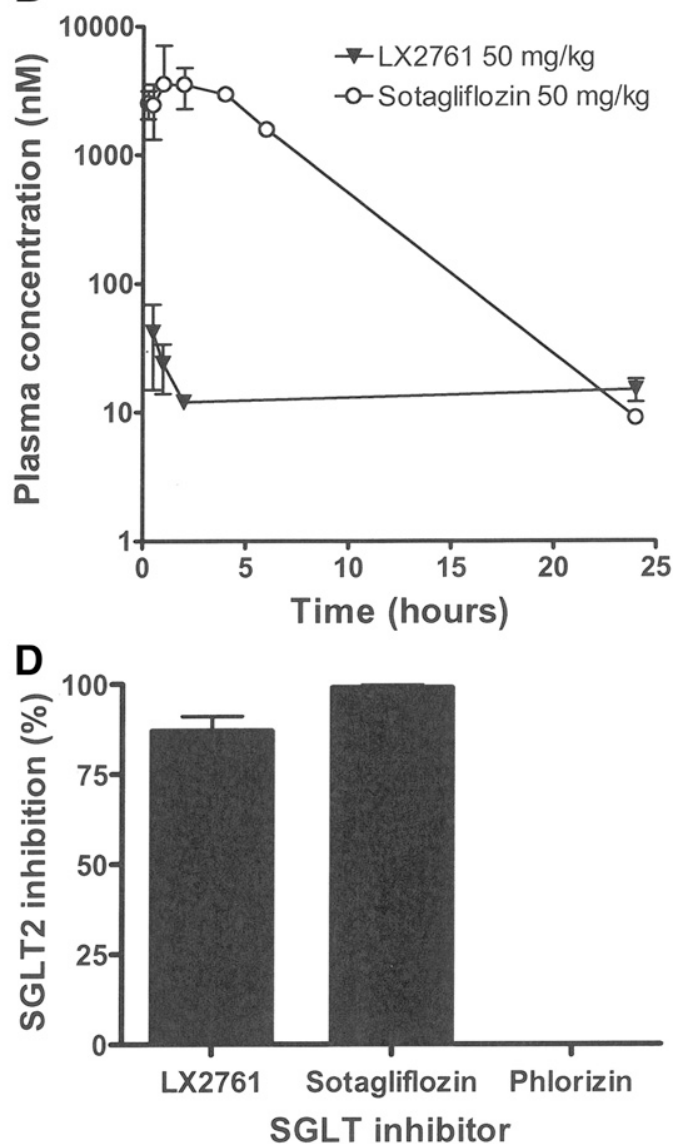

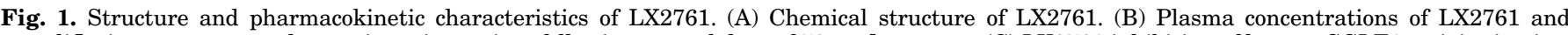

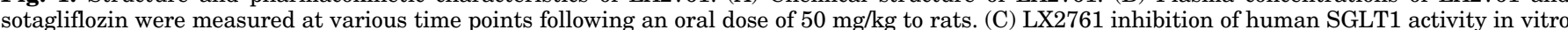

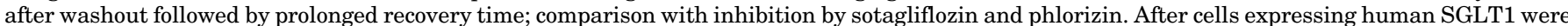

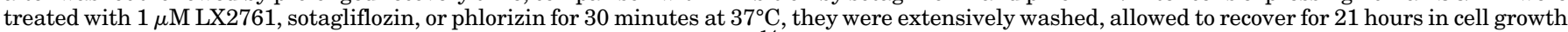

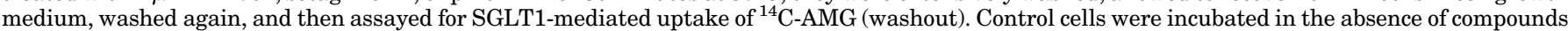

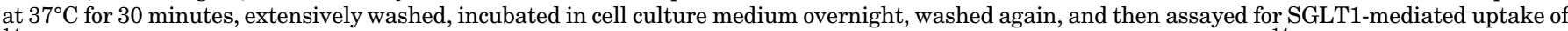

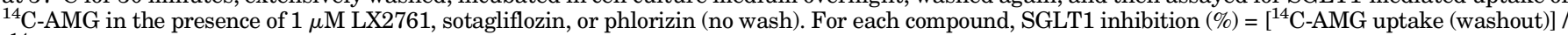

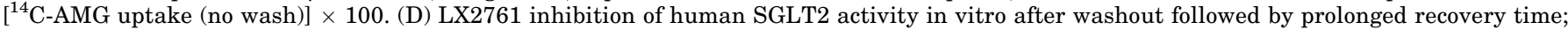

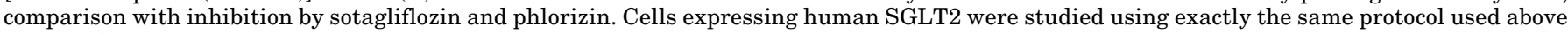
in Fig. 1C.

4 consecutive days were challenged with a glucose-containing meal 6 hours after the final gavage dose, as outlined in Supplemental Fig. 1A. The highest dose of LX2761, $1.5 \mathrm{mg} / \mathrm{kg}$, was associated with a decrease in food consumption on day 1 that returned to normal by day 3 (Supplemental Fig. 1B), and with a loss of body weight on day 2 that was returning to normal by day 4 (Supplemental Fig. 1C). The decreases in food consumption and body weight in mice receiving $1.5 \mathrm{mg} / \mathrm{kg}$ of LX2761 were accompanied by diarrhea in most mice (Table 4). On day 4, LX2761-treated mice responded to the glucosecontaining meal challenge with significantly decreased blood glucose excursions, numerically increased cecal glucose levels, and significantly decreased cecal pH (Supplemental Figs. 1, D-F). All of these findings are consistent with inhibition of SGLT1-mediated intestinal glucose absorption by LX2761.

To determine if LX2761 could be delivered at a dose that significantly lowered glucose excursions without causing diarrhea, we first evaluated stool consistency during treatment of male mice with various doses of LX2761. As shown in Table 4, diarrhea was rarely observed in mice receiving an LX2761 dose of $0.15 \mathrm{mg} / \mathrm{kg}$, and was not observed in any mice receiving a lower dose. We then examined whether doses of LX2761 $<0.15 \mathrm{mg} / \mathrm{kg}$ could lower glucose excursions in healthy mice, and whether the inhibitory effect of these low doses could last for a prolonged period of time despite ad lib feeding, as suggested by the in vitro washout studies. As shown in Fig. 2A, LX2761 was delivered once daily by oral

TABLE 1

LX2761 inhibits SGLT-mediated glucose transport

\begin{tabular}{lcccrr}
\hline \multirow{2}{*}{ Species } & \multicolumn{2}{c}{ SGLT1 } & & \multicolumn{2}{c}{ SGLT2 } \\
\cline { 2 - 3 } \cline { 5 - 5 } & $\mathrm{IC}_{50}$ & $N$ & & IC $_{50}$ & $N$ \\
\hline & $n M$ & & $n M$ & \\
Human $^{a}$ & $2.2 \pm 0.7$ & 7 & $2.7 \pm 0.8$ & 6 \\
Mouse $_{\text {Rat }}$ & $3.7 \pm 0.9$ & 6 & & $1.0 \pm 0.3$ & 6 \\
Dog & $5.7 \pm 1.4$ & 3 & & $1.1 \pm 0.4$ & 3 \\
Monkey & $5.1 \pm 0.7$ & 7 & & $1.8 \pm 0.6$ & 10 \\
\hline
\end{tabular}

$\mathrm{IC}_{50}$, concentration causing half-maximal inhibition; $N$, number of determinations.

${ }^{a}$ Data are from Goodwin et al., 2017 
TABLE 2

Pharmacokinetic parameters after rats received a $1 \mathrm{mg} / \mathrm{kg}$ intravenous dose of LX2761 or sotagliflozin

\begin{tabular}{lccccc}
\hline \multicolumn{1}{c}{ Compound } & $N$ & Half-Life & $\mathrm{AUC}_{0-\infty}$ & $\mathrm{CL}$ & $V_{s s}$ \\
\hline & \multicolumn{1}{c}{$h r$} & $n M^{*} h r$ & $\begin{array}{c}\text { ml/min } \\
\text { per kilogram }\end{array}$ & $l / k g$ \\
LX2761 & 4 & $1.2 \pm 0.5$ & $581 \pm 117$ & $49.1 \pm 10.6$ & $2.2 \pm 0.3$ \\
Sotagliflozin & 4 & $0.9 \pm 0.09$ & $1847 \pm 132$ & $21.3 \pm 1.5$ & $1.4 \pm 0.07$ \\
\hline
\end{tabular}

$N$, number of animals; CL, clearance; Vss, volume at steady state.

gavage at 5:00 PM for 5 consecutive days; after the last dose, the mice were fed ad lib overnight and then challenged with an OGTT 15 hours later. As shown in Fig. 2, B and C, LX2761 doses $\leq 0.15 \mathrm{mg} / \mathrm{kg}$ significantly decreased OGTT glucose excursions. Body weights were not significantly altered by LX2761 treatment in either of these studies (Supplemental Fig. 2).

LX2761 dosed alone at $0.15 \mathrm{mg} / \mathrm{kg}$ led to a modest rise in systemic levels of aGLP-1 (Fig. 3). We considered the possibility that this dose of LX2761 might stimulate a marked release of GLP-1 from the intestine into the portal circulation, but rapid degradation of the released aGLP-1 could prevent detection of this increase by the time aGLP-1 reached the systemic circulation for sampling. To test this hypothesis, we dosed $0.15 \mathrm{mg} / \mathrm{kg}$ LX2761 along with $30 \mathrm{mg} / \mathrm{kg}$ of sitagliptin, a DPP4 inhibitor that prevents degradation of aGLP-1. As shown in Fig. 3A, single doses of LX2761 and sitagliptin given in combination to mice induced a strongly synergistic increase in aGLP-1 levels after an oral glucose challenge relative to the modest increase observed when LX2761 or sitagliptin were dosed alone. This synergistic increase of aGLP-1 levels was maintained but not enhanced by providing a 14-day course of the LX2761/sitagliptin combination prior to oral glucose challenge (Fig. 3B).

LX2761 was studied in rats to test the effect of the compound in a different species. HGD-fed adult rats received LX2761 or vehicle by oral gavage once daily for 4 days. After an overnight fast, the rats received their fifth dose of LX2761 followed in 30 minutes by an OGTT (Supplemental Fig. 3A). Food consumption was comparable among all groups over the first 3 days of the study (Supplemental Fig. 3B), consistent with the similar differences in body weight from day-1 values (Supplemental Fig. 3C). In addition, stool consistency was evaluated, and although diarrhea was occasionally observed in rats receiving the higher LX2761 doses, no diarrhea was observed in rats dosed daily with $0.0625 \mathrm{mg} / \mathrm{kg}$ of LX2761 (Table 4). After the OGTT glucose challenge on day 5 , rats treated with each dose of LX2761 exhibited a significant decrease in blood glucose excursions (Supplemental Fig. 3D) along with an increase in circulating tGLP-1 levels (Supplemental Fig. 3E), similar to data obtained in mouse studies.
Using the same experimental design, one additional study re-examined the effect of $0.0625 \mathrm{mg} / \mathrm{kg}$ and also studied two lower LX2761 doses, and found that a dose as low as $0.0225 \mathrm{mg} / \mathrm{kg}$ significantly lowered glucose excursions (Supplemental Fig. $3 \mathrm{~F}$ ), and at the same time raised tGLP-1 levels (Supplemental Fig. 3G), during the OGTT; body weight did not differ among the four groups of rats during the course of this study (Supplemental Fig. $3 \mathrm{H})$.

To test the effect of LX2761 on glycemic control in a mouse model of diabetes, we used STZ to induce diabetes in adult mice maintained on HGD. In the initial study, we evaluated the effect of LX2761 on the progression of early-onset diabetes. We randomized 31 STZ-treated mice, diagnosed as diabetic on the basis of baseline fed-glucose levels $>200 \mathrm{mg} / \mathrm{dl}$ (mean glucose $=287 \mathrm{mg} /$ dl on day 1 ), to receive either vehicle, $1.5 \mathrm{mg} / \mathrm{kg} \mathrm{LX} 2761$, or $3 \mathrm{mg} / \mathrm{kg}$ LX2761 once daily by oral gavage. A schematic depiction of the study design is shown in Fig. 4A. LX2761 had no significant effect on either food consumption or body weight of these diabetic mice throughout the study (Supplemental Fig. 4, A and B). OGTTs performed on treatment days 21 (Fig. 4B) and 39 (Supplemental Fig. 4C) showed that LX2761 significantly and dose-dependently decreased glucose excursions in fed mice. After 32 days of LX2761 treatment, both the $1.5-$ and $3-\mathrm{mg} / \mathrm{kg}$ doses were associated with significant decreases in fasting blood glucose levels (Fig. 4C) and with significant slowing of the rise in $\mathrm{A} 1 \mathrm{C}$ levels (Fig. 4D) relative to levels observed in the vehicletreated group. LX2761 did not alter levels of plasma tGLP-1 obtained 2 hours after glucose challenge on the final study day (Supplemental Fig. 4D) but did increase levels of cecal glucose (Fig. 4E) and decrease levels of cecal pH (Fig. 4F) measured in cecal contents harvested at the necropsy performed at that time.

We also explored the effect of LX2761 on glycemic control of mice with well-established STZ-induced diabetes. We randomized 38 diabetic mice with $\mathrm{A} 1 \mathrm{C}>5.7 \%$ to receive either vehicle or LX2761; A1C levels were quite high in the three groups at baseline, measuring $9.6 \pm 1.5 \%(n=12), 9.3 \pm 1.4 \%$ $(n=13)$, and $9.3 \pm 1.6 \%(n=13)$ in the vehicle, $1.5 \mathrm{mg} / \mathrm{kg}$ LX2761-, and $3 \mathrm{mg} / \mathrm{kg}$ LX2761-treated groups, respectively. A schematic depiction of the study design is shown in Fig. 5A. Mice treated with LX2761 exhibited trends toward increased food consumption and body weight relative to the vehicletreated group during the course of the study (Supplemental Fig. 5, A and B). Nine mice required euthanasia during the study owing to a marked decrease in food consumption and body weight, and mouse survival was related to the dose of LX2761 received, with survival significantly improved in the $3 \mathrm{mg} / \mathrm{kg}$ LX2761 group relative to the vehicle group (Fig. 5B). To assess whether LX2761 improves glycemic control of these diabetic mice, we measured both blood glucose and A1C levels. Compared with the vehicle group, LX2761 treatment significantly

TABLE 3

Pharmacokinetic parameters after rats received a $50 \mathrm{mg} / \mathrm{kg}$ oral dose of LX2761 or sotagliflozin

\begin{tabular}{cccccccc}
\hline Compound & $N$ & Half-Life & $T_{\max }$ & $C_{\max }$ & $\mathrm{AUC}_{0-\text { last }}$ & $\mathrm{AUC}_{0-\infty}$ & $\% \mathrm{~F}$ \\
\hline & & $h r$ & $h r$ & $n M$ & $n M^{*} h r$ & $n M^{*} h r$ & $\%$ \\
LX2761 & 5 & N/A & $0.6 \pm 0.2$ & $37 \pm 27$ & $424 \pm 134$ & N/A & $<5$ \\
Sotagliflozin & 4 & $2.42 \pm 0.08$ & $1.88 \pm 1.55$ & $11918 \pm 6250$ & $52027 \pm 6722$ & $52103 \pm 6712$ & $56 \pm 7$
\end{tabular}

$N$, number of animals; \%F, \% bioavailable; N/A, value could not be calculated owing to low exposure. 
TABLE 4

Frequency of diarrhea in mice or rats treated with LX2761

\begin{tabular}{llllll}
\hline \multirow{2}{*}{ Species } & LX2761 dose & \multicolumn{4}{c}{ Study Day } \\
\cline { 3 - 5 } & & Day 1 & Day 2 & Day 3 & Day 4 \\
\hline \multirow{4}{*}{ Mice } & $m g / k g$ & & & \\
& $1.5^{a}$ & 9 of 10 & 5 of 10 & 3 of 10 & \\
& $0.15^{c}$ & 0 of 15 & 2 of 15 & 0 of 15 & 0 of 5 \\
& $0.1^{b}$ & 0 of 5 & 0 of 5 & 0 of 5 & 0 of 5 \\
& $0.075_{b}$ & 0 of 5 & 0 of 5 & 0 of 5 & 0 of 5 \\
& $0.05^{b}$ & 0 of 5 & 0 of 5 & 0 of 5 & 0 of 5 \\
& $0.015^{a}$ & 0 of 10 & 0 of 10 & 0 of 10 & \\
& $0.0^{a}$ & 0 of 10 & 0 of 10 & 0 of 10 & \\
& $0.25^{b}$ & 1 of 5 & 1 of 5 & 2 of 5 & \\
& $0.125^{b}$ & 1 of 5 & 1 of 5 & 0 of 5 & \\
& $0.0625^{b}$ & 0 of 5 & 0 of 5 & 0 of 5 & \\
& $0.0^{b}$ & 0 of 5 & 0 of 5 & 0 of 5 & \\
& & & & &
\end{tabular}

${ }^{a} 8: 00$ AM dosing

${ }^{b}$ 5:00 PM dosing

${ }^{c} 10$ dosed at 8:00 AM, 5 dosed at 5:00 PM

decreased both baseline blood glucose levels and blood glucose excursions during an OGTT performed in the fed state on day 20, 15 hours after LX2761 dosing (Fig. 5C). On day 30, the $3-\mathrm{mg} / \mathrm{kg}$ LX2761 group also exhibited significantly improved A1C values (Fig. 5D). On day 49, an OGTT performed 6 hours after the last LX2761 dose, designed to directly test whether LX2761 inhibited intestinal glucose absorption in fasted mice, showed that the LX2761-treated groups had lower baseline fasting blood glucose levels (Fig. 5E) and again showed decreased blood glucose excursions (Supplemental Fig. 5C); in addition, 2 hours after glucose challenge, LX2761 treatment was associated with increased plasma tGLP-1 (Fig. 5F), increased cecal glucose (Fig. 5G), and decreased cecal pH (Fig. $5 \mathrm{H})$. Because preliminary studies indicated that wire-grid flooring compromised the survival of STZ-diabetic mice, we did not perform a quantitative analysis of stool consistency for either study using STZ-diabetic mice; however, we did examine all mice and cages on a daily basis in both studies. Qualitatively, we only observed evidence of diarrhea in a few cages during the first few days of each study, and we never observed wet anal fur during daily examination of each mouse, suggesting that there were no instances of a stool consistency score of 3.

Gradual escalation of LX2761 dose did not have an obvious effect on food consumption or body weight of mice (Supplemental Fig. 6, A and B). However, gradual escalation of the LX2761 dose to $0.5,0.6$, and $0.7 \mathrm{mg} / \mathrm{kg}$ significantly decreased the percentage of study days when mice fed HGD had diarrhea (Fig. 6A; Supplemental Table 1). We considered that gradual escalation of the LX2761 dose led to gradual escalation of 1) the amount of glucose reaching the cecum and 2) the number of cecal bacteria that ferment glucose, and we hypothesized that increasing the number of these glucose-fermenting bacteria is a way to decrease diarrhea and other symptoms associated with impaired intestinal glucose absorption. Because humans with SGLT1 deficiency may accelerate their tolerance to glucose-containing diets over time with the use of probiotic supplements, usually containing $L$. acidophilus (Xin and Wang, 2011), we studied the role of L. acidophilus in LX2761-related diarrhea. Male mice receiving LX2761 at a daily dose of $0.5 \mathrm{mg} / \mathrm{kg}$ exhibited a modest increase in the abundance of $L$. acidophilus when their cecal contents were
A

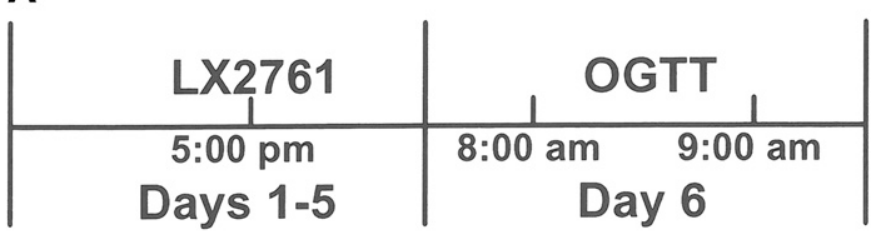

B
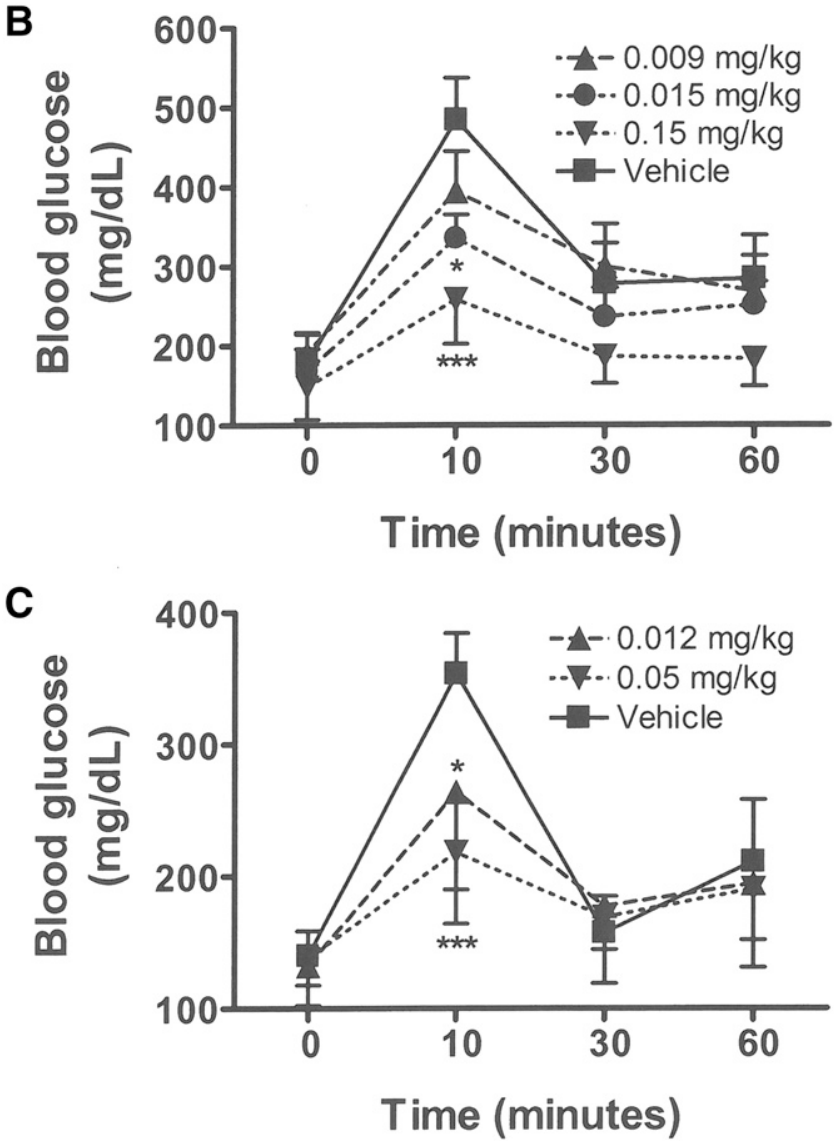

Fig. 2. LX2761 doses $\leq 0.15 \mathrm{mg} / \mathrm{kg}$ can decrease OGTT glucose excursions. (A) Schematic depiction of study design. Adult male mice fed HGD for 6 days prior to study were randomized into three or four treatment groups by body weight. All mice received 5 daily doses of either LX2761 or vehicle by oral gavage, and all mice were fed ad lib during the 15-hour interval between the final dose and the OGTT. (B) Glucose excursions from OGTTs performed on mice (4-5/group) that received either vehicle or LX2761 at a dose of $0.15,0.015$, or $0.009 \mathrm{mg} / \mathrm{kg}$. (C) Glucose excursions from OGTTs performed on mice (8-9/group) that received either vehicle or LX2761 at a dose of 0.05 or $0.012 \mathrm{mg} / \mathrm{kg}$. For (B) and (C), where glucose excursions among groups were compared as glucose $\mathrm{AUC}_{0-60}$ minutes values, ${ }^{*} P<0.05$ and $* * * P<0.001$ versus the vehicle-treated group.

cultured after 14 days of treatment (Supplemental Table 2). Nevertheless, pretreatment with a probiotic supplement containing $L$. acidophilus did not significantly decrease the prevalence of diarrhea in LX2761-treated mice (Supplemental Table 3). Another potential way to increase the number of cecal bacteria that ferment glucose is to include resistant starches in the diet. Resistant starches are dietary carbohydrates so named because they resist digestion in the small intestine; this allows them to reach the large intestine where they are fermented to short-chain fatty acids (SCFA) by colonic bacteria (Topping et al., 2003; Zhou et al., 2008). To test this hypothesis, we first studied the ability of dietary 

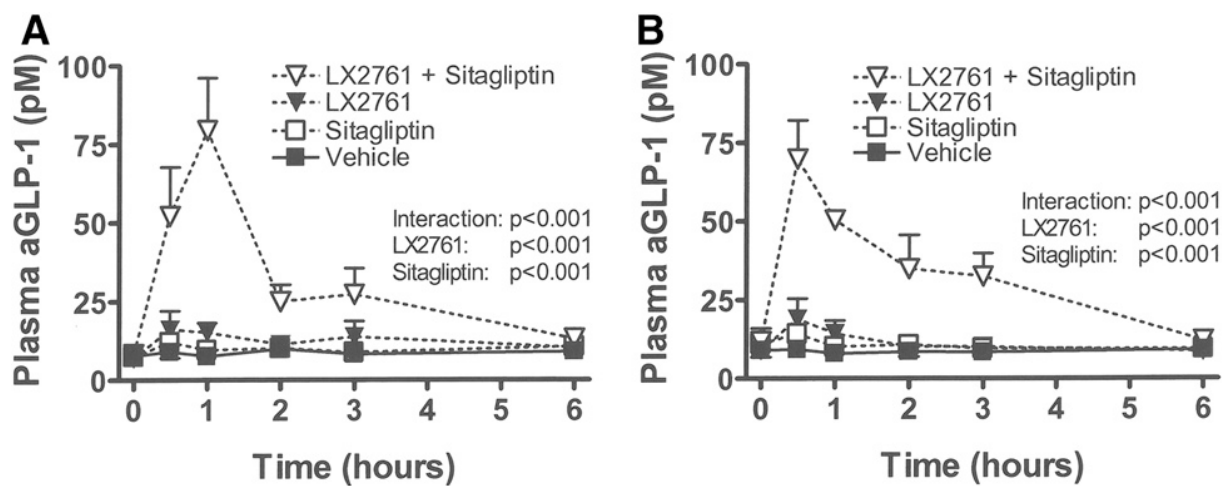

Fig. 3. The combination of LX2761 and sitagliptin synergistically increases aGLP-1 levels between 0 and 6 hours after an oral glucose challenge. Adult male mice (5/group) received 1 (A) or 14 (B) daily doses of either LX2761 $(0.15 \mathrm{mg} / \mathrm{kg})$, sitagliptin (30 mg/kg), the combination of LX2761 and sitagliptin $(0.15 \mathrm{mg} / \mathrm{kg}+30 \mathrm{mg} / \mathrm{kg}$, respectively), or vehicle by oral gavage. Thirty minutes after the last dose, all mice received $4 \mathrm{~g} / \mathrm{kg}$ glucose by oral gavage. Levels of aGLP-1 obtained at various times after the glucose challenge are plotted in the panels. For each treatment group, the aGLP-1 time-course data were converted to aGLP-1 $\mathrm{AUC}_{0-6}$ hours values, which were then analyzed by two-way ANOVA. An interaction between the effects of LX2761 and sitagliptin on postprandial aGLP-1 levels was considered significant when $P<0.05$.

pretreatment with resistant starches RS2 and RS4 to prevent diarrhea in mice treated with LP-945013 (Fig. 6B), a compound structurally similar to LX2761 that potently inhibits human SGLT1- and SGLT2-mediated glucose uptake with $\mathrm{IC}_{50}$ values of $3.3 \mathrm{nM}$ and $2.5 \mathrm{nM}$, respectively. Oral administration of LP-945013 to mice resulted in pharmacokinetic parameters (Supplemental Fig. 7A; Supplemental Table 4) and an insignificant increase in UGE (Supplemental Fig. 7B) that were quite similar to results observed after oral administration of LX2761 (Goodwin et al., 2017). During the first 3 days that mice were fed HGD containing either RS2 (HGDRS2) or RS4 (HGD-RS4), no mice exhibited diarrhea (Supplemental Table 5). After 21 days of pretreatment, all mice were placed on HGD and began to receive either vehicle or LP-945013. In mice fed HGD or HGD-RS2 during the pretreatment period, LP-945013 treatment was often associated with diarrhea; in contrast, diarrhea was not observed during LP-945013 treatment of any mice pretreated with HGDRS4 (Fig. 6C; Supplemental Table 5). On the basis of these results, the same protocol was used to determine the ability of RS4 pretreatment to prevent diarrhea in mice treated with LX2761; results are presented in Fig. 6D and Supplemental Table 6. Of the 100 mice fed HGD during the pretreatment period, LX2761 treatment was associated with diarrhea in 92, 43,39 , and 66 mice on days 1 through 4, respectively. In general, the prevalence of diarrhea in these mice decreased with time and with a lower LX2761 dose (Supplemental Table 6). In contrast, of the 100 mice fed HGD-RS4 during the pretreatment period, LX2761 treatment was associated with diarrhea in only $15,7,6$, and 0 mice on days 1 through 4 , respectively, values that are significantly less than those observed in mice fed HGD during the pretreatment period. In these mice, the prevalence of diarrhea also decreased with time (Supplemental Table 6). To determine if RS4 pretreatment alters the effect of LX2761 on OGTT glucose excursions and intestinal glucose absorption, mice were studied using the same protocol. All mice then underwent an OGTT 30 minutes after the last LX2761 dose, and 1 hour after glucose challenge the cecal contents of all mice were collected for analysis of cecal glucose and pH. As is shown in Supplemental Fig. 8, glucose excursions were quite similar for mice fed either HGD or HGDRS4 during the pretreatment period, and LX2761 treatment decreased glucose excursions and cecal $\mathrm{pH}$, and increased cecal glucose, in a similar manner in these two groups of mice.

\section{Discussion}

LX2761 was designed to remain in the intestinal lumen after oral delivery to inhibit SGLT1, the transporter primarily responsible for absorption of dietary glucose (Zambrowicz et al., 2012; Goodwin et al., 2017). Although LX2761 is a potent inhibitor of both SGLT1 and SGLT2 across mammalian species, SGLT1 selectivity is achieved here because SGLT2 is not appreciably expressed by the intestinal epithelium (Chen et al., 2010; Wright et al., 2011). Evidence that LX2761 remains in the intestine is provided by pharmacodynamic and pharmacokinetic studies in mice (Goodwin et al., 2017), along with pharmacokinetic studies in rats (present work), that demonstrate the poor bioavailability of LX2761 in rodents.

Mice lacking SGLT1 responded to an oral glucose challenge with decreased blood glucose excursions, increased cecal glucose levels, decreased cecal $\mathrm{pH}$, and increased plasma levels of GLP-1 (Powell et al., 2013a,b). As expected, oral dosing of LX2761 followed by an oral glucose challenge resulted in these same changes in rodents (Goodwin et al., 2017; present work), consistent with inhibition of intestinal SGLT1 and reminiscent of findings in humans and other species treated with the dual SGLT1/SGLT2 inhibitor sotagliflozin (Zambrowicz et al., 2012, 2015; Powell et al., 2013b, 2014). Importantly, studies reported here showed that healthy mice receiving a single evening oral dose of LX2761 and allowed to eat ad lib overnight still showed decreased glucose excursions after an oral glucose challenge delivered 15 hours later. This finding, consistent with the inability of washing to reverse LX2761-mediated inhibition of glucose transport by SGLT1-expressing HEK293 cells in vitro, suggests that a single LX2761 dose delivered immediately before the first meal of the day may inhibit SGLT1-mediated glucose uptake from all meals ingested during the rest of the day.

Mechanistically, LX2761 inhibits intestinal SGLT1, resulting in increased glucose delivery to the cecum, where the excess glucose is fermented to SCFAs, which are responsible for the lower cecal $\mathrm{pH}$. These SCFAs then bind to GPR41 and 
A

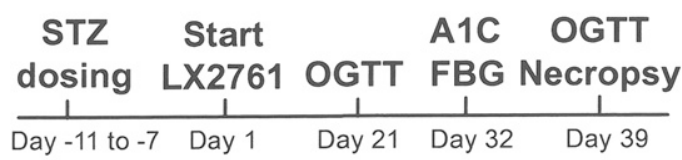

C

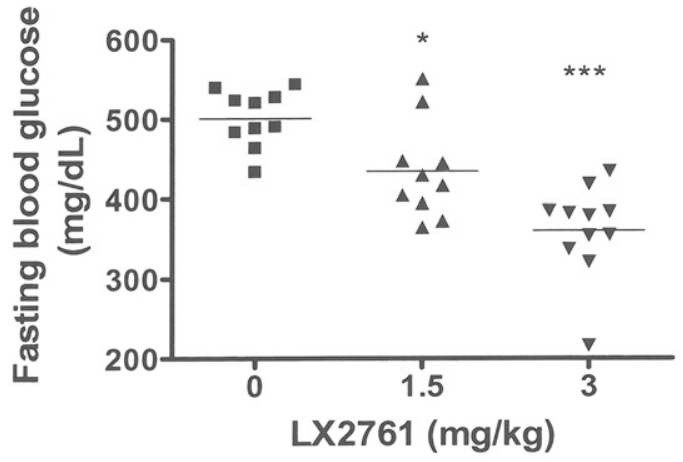

E

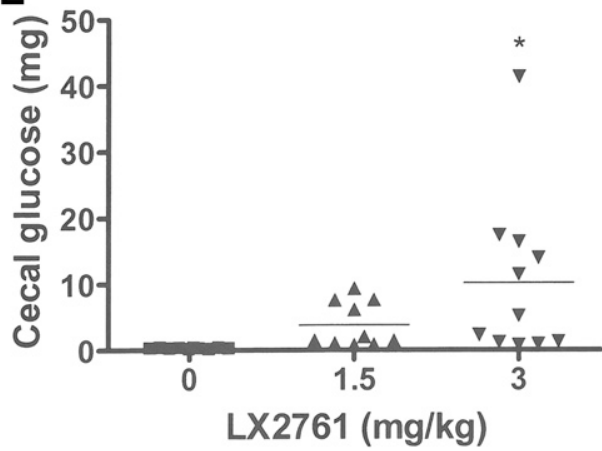

B

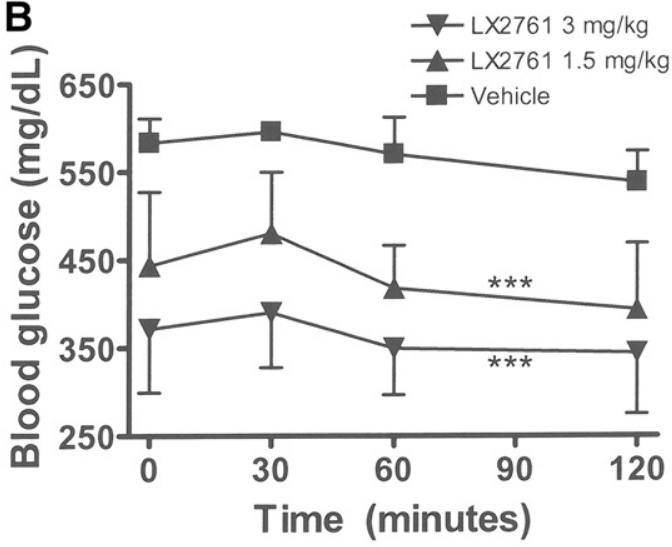

D

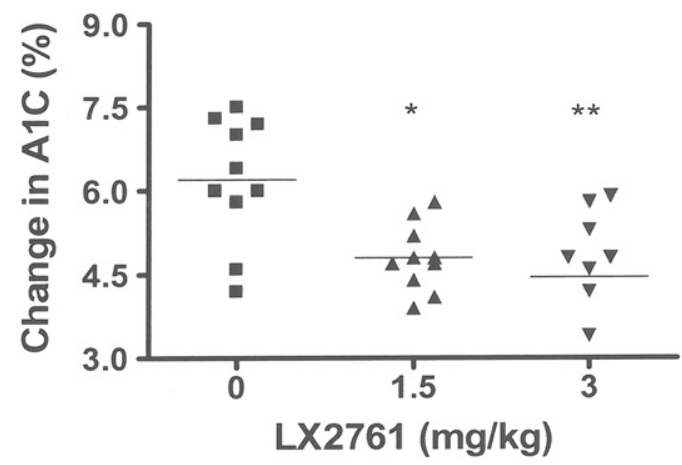

F

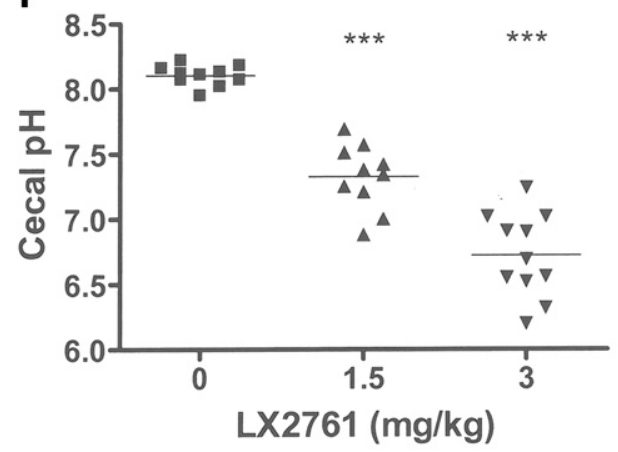

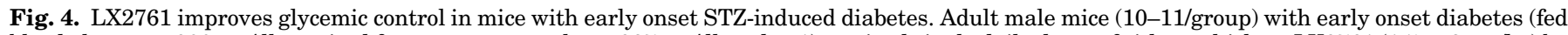

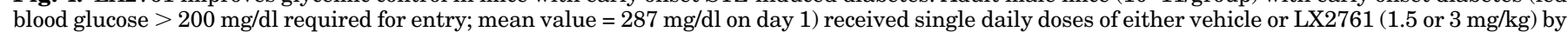

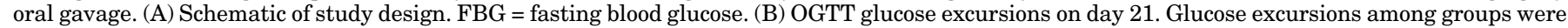

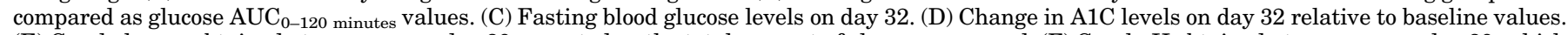

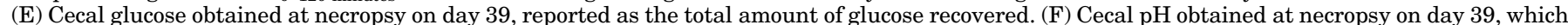

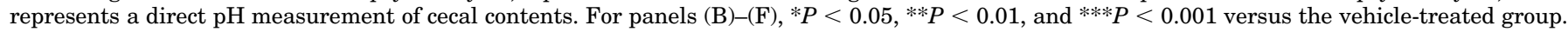

GPR43, which confer the ability of SCFAs to stimulate GLP-1 release from the colon (Zhou et al., 2006, 2008; Lin et al., 2012; Tolhurst et al., 2012; Powell et al., 2013b). Although LX2761 modestly increased circulating GLP-1 levels in studies presented here, the doses used $(0.15 \mathrm{mg} / \mathrm{kg}$ in mice, $0.125 \mathrm{mg} / \mathrm{kg}$ in rats) were associated with occasional episodes of diarrhea. However, circulating GLP-1 levels were markedly and synergistically increased in mice when this same $0.15-\mathrm{mg} / \mathrm{kg}$ dose of LX2761 was combined with sitagliptin, a DPP4 inhibitor that prevents aGLP-1 degradation and inactivation (Zambrowicz et al., 2013). These data suggest that this profound LX2761mediated increase in GLP-1 release into the portal circulation can only be detected in the systemic circulation if a DPP4 inhibitor prevents rapid GLP-1 degradation. On the basis of these results, it seems probable that LX2761 doses $\leq 0.1 \mathrm{mg} / \mathrm{kg}$, which were not associated with diarrhea in mice, will also significantly increase the release of GLP-1 into the portal circulation. It is important to emphasize that increased release of GLP-1 directly into the portal circulation may be the optimal way to deliver this peptide. GLP-1 receptors are expressed throughout the portal circulation, and in particular are present on vagal afferents that innervate the intestine. Further, vagotomy decreases the effect of GLP-1 in mammals; in humans, vagotomy impaired the ability of exogenous GLP-1 to not only decrease appetite and gastric emptying but also to increase secretion of insulin and glucagon (Balkan and $\mathrm{Li}$, 2000; Abbott et al., 2005; Holmes et al., 2009; Plamboeck et al., 2013). These results suggest that local GLP-1 activity in the 
A
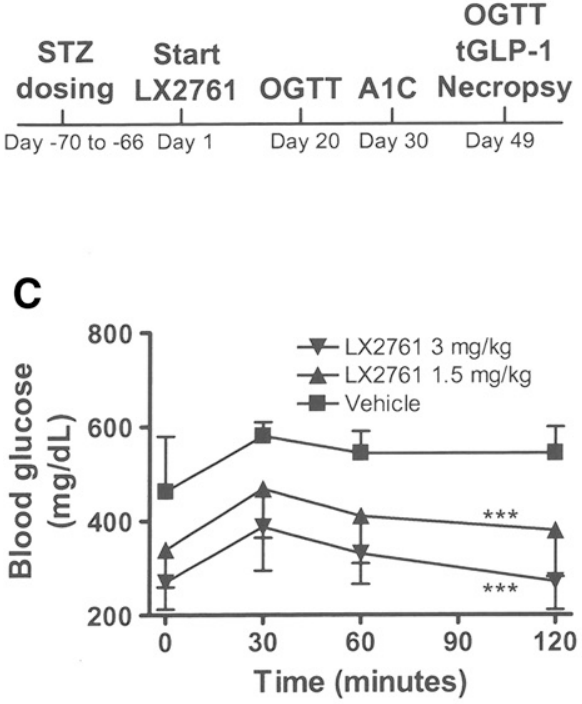

E
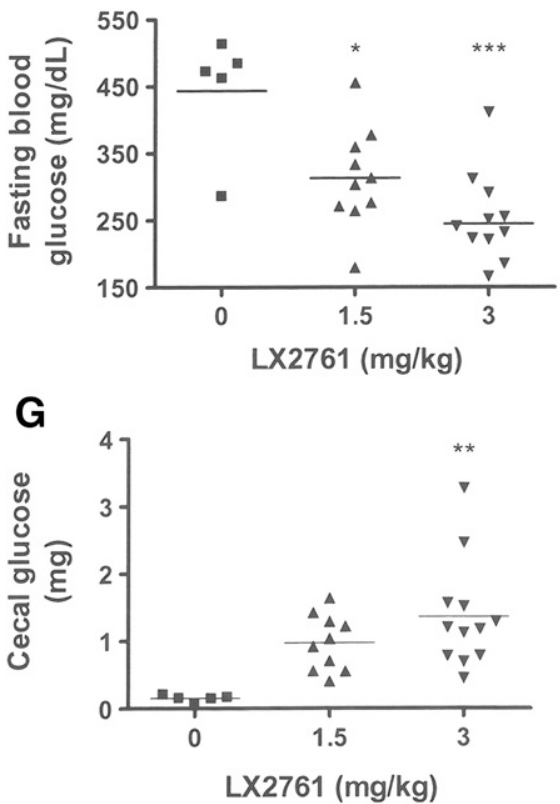

B
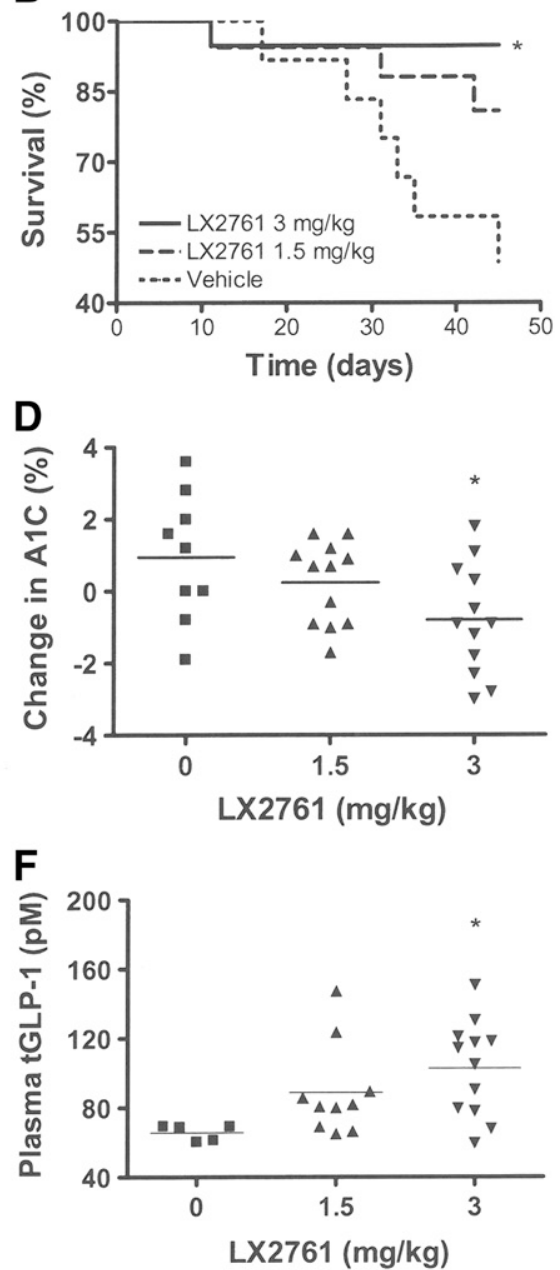

H

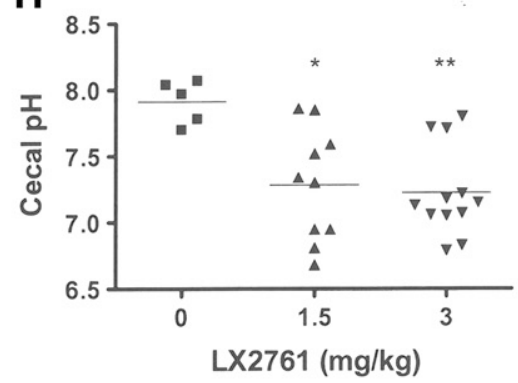

Fig. 5. LX2761 improves glycemic control in mice with well-established STZ-induced diabetes. Adult male mice (12-13/group at randomization) with well-established diabetes $(\mathrm{A} 1 \mathrm{C}>5.7 \%$ required for entry, mean $=9.4 \%$ on day 1) received single daily doses of vehicle or LX2761 (1.5 or $3 \mathrm{mg} / \mathrm{kg})$ by oral gavage. (A) Schematic depiction of study design. (B) Kaplan and Meier survival curve for the three groups of study mice. (C) OGTT glucose excursions on day 20. Glucose excursions among groups were compared as glucose $\mathrm{AUC}_{0-120}$ minutes values. (D) Change in $\mathrm{A} 1 \mathrm{C}$ levels on day 32 relative to baseline values. On day 49 , the final study day, samples were obtained to measure (E) fasting blood glucose; (F) plasma tGLP-1; (G) cecal glucose, reported as the total amount of glucose recovered; and (H) cecal $\mathrm{pH}$, which represents a direct $\mathrm{pH}$ measurement of cecal contents. For panels (B) $-(\mathrm{H}), * P<0.05$, $* * P<0.01$, and $* * * P<$ 0.001 versus the vehicle-treated group. portal system is necessary to achieve the maximal antidiabetic effects of this peptide.

LX2761 treatment improved glycemic control when introduced either early or late in the course of STZ-induced diabetes. In LX2761-treated mice, significantly lower levels of fed and fasting blood glucose contributed to the significantly slower rise in A1C levels; this is similar to the observation that $\alpha$-glucosidase inhibitors, which also act by inhibiting intestinal glucose absorption, improve $\mathrm{A} 1 \mathrm{C}$ levels by lowering fasting blood glucose in addition to lowering postprandial glucose excursions (Van De Laar et al., 2005). Importantly, LX2761 treatment did not simply improve laboratory values in mice with long-standing STZ-induced diabetes, it also significantly improved their survival. Of interest, relatively high doses of
LX2761 were required to show efficacy in STZ-diabetic mice, but little diarrhea was observed despite the higher doses; this is probably explained by the higher SGLT1 expression observed in diabetic rodents (Burant et al., 1994; Debnam et al., 1995). Higher SGLT1 expression was also reported in diabetic humans (Dyer et al., 2002), suggesting that higher doses may be required for LX2761 to have an effect in humans with diabetes.

Diarrhea was a common side effect in mice and rats treated with LX2761 when on a glucose-containing diet, consistent with the experience of individuals with SGLT1 deficiency (Wright et al., 2011; Xin and Wang, 2011). In general, the frequency and severity of diarrheal episodes were dosedependent and decreased with time during multidose studies 
A
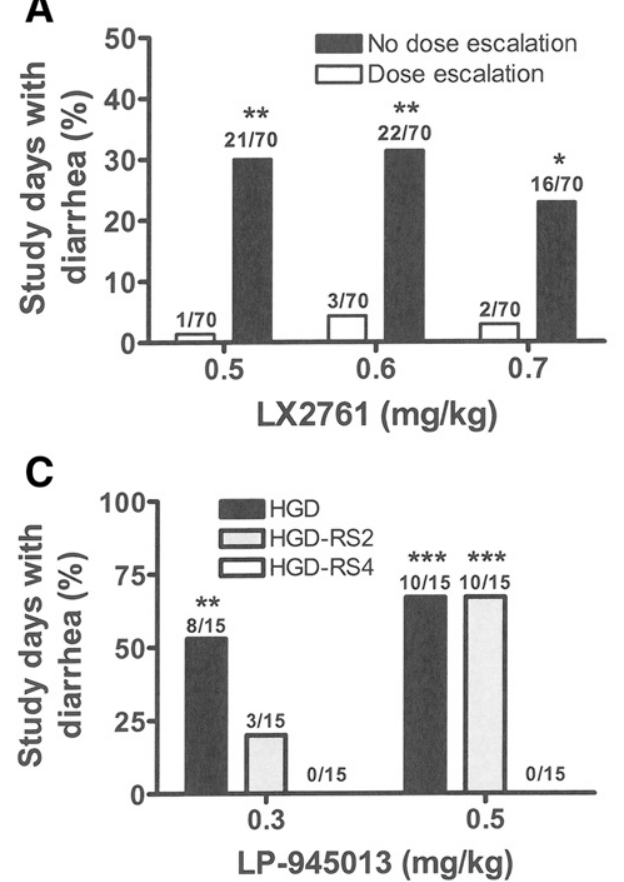

B
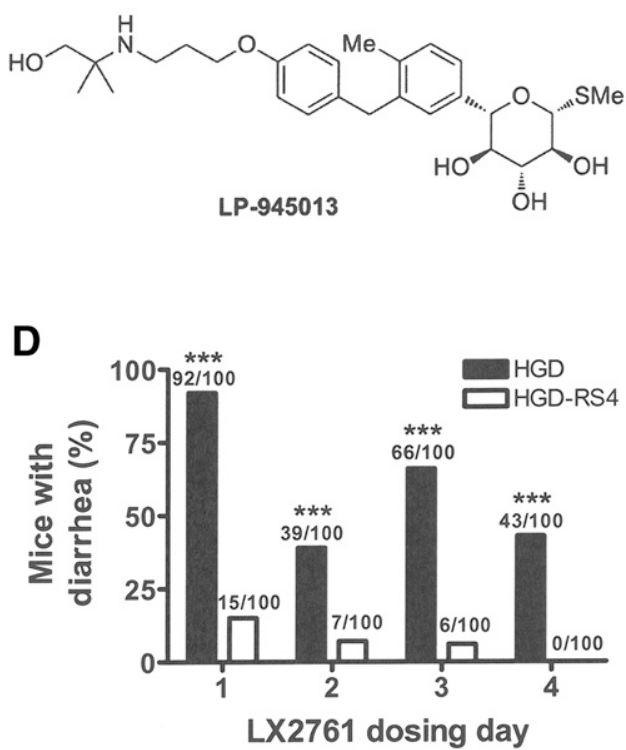

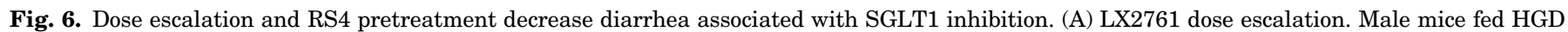

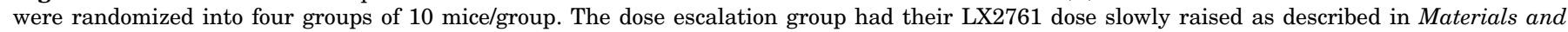

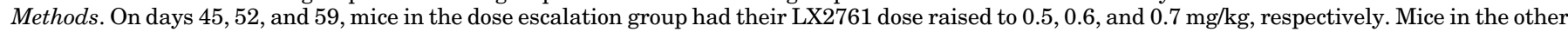

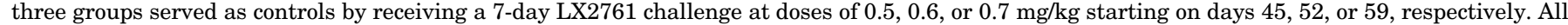

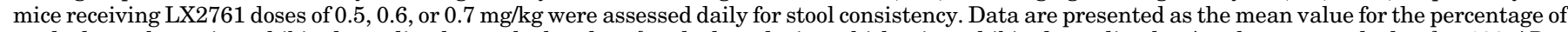

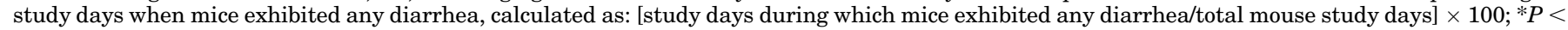

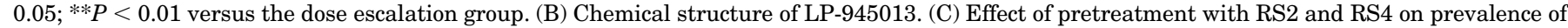

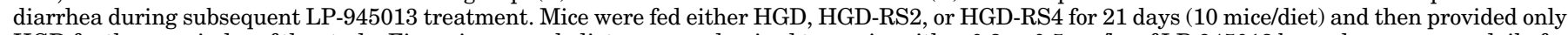

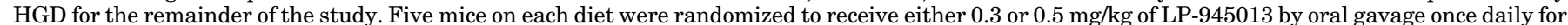

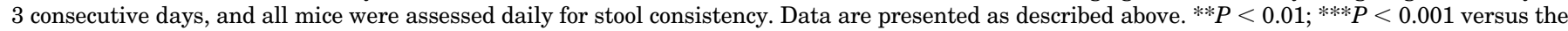

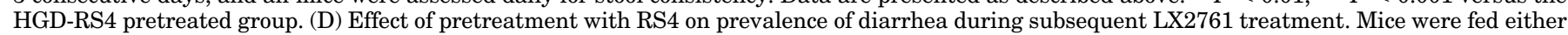

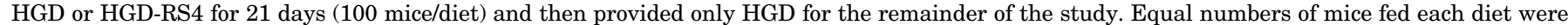

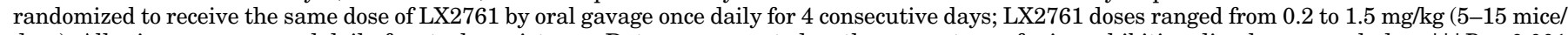

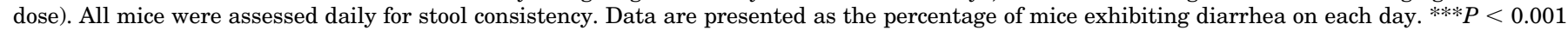
versus the HGD-RS4 pretreated group.

in rodents. This suggested that gradual dose escalation would lower diarrhea frequency, a hypothesis supported by the dose escalation study reported here. Humans with SGLT1 deficiency also tolerate glucose-containing diets over time, a process possibly accelerated by use of probiotic supplements such as L. acidophilus (Xin and Wang, 2011). Although we observed a qualitative increase in abundance of $L$. acidophilus in cecal contents from LX2761-treated mice, providing them with this probiotic supplement did not decrease the prevalence of diarrhea. Nevertheless, because we hypothesized that intestinal tolerance to LX2761 is developed by selecting intestinal bacteria that use glucose as an energy source, we tried another approach, by delivering dietary resistant starch to the colon to provide glucose that would allow glucosefermenting bacterial species to flourish. Data presented here clearly show that mice pretreated with RS4 did not develop diarrhea during the pretreatment period and they had much less diarrhea during subsequent LX2761 treatment after RS4 was removed from the diet. Although short-term exposure to dietary RS4 was associated with lower postprandial glucose and insulin levels in humans (Al-Tamimi et al., 2010), in our hands RS4 pretreatment itself had no effect on postprandial glucose excursions; LX2761 treatment alone decreased postprandial glucose. The above hypothesis is consistent with the ability of dietary RS4 to significantly alter the composition of fecal microbial populations and increase fecal SCFA levels in humans with signs of metabolic syndrome (Upadhyaya et al., 2016). In our hands, RS2 was less able than RS4 to prevent diarrhea, but these two resistant starches have very different effects on composition of the fecal microbiota (Martinez et al., 2010); most probably, differences in their chemical properties explain the differential effects of RS2 and RS4 on microbiome composition, perhaps by differences in fermentability. Taken together, these data suggest that patients pretreated with dietary RS4 will tolerate higher initial doses of LX2761 without experiencing diarrhea.

Other SGLT1 inhibitors have been reported. These compounds were either nonabsorbable polymeric conjugates (Ikumi et al., 2008; Sakuma et al., 2010) or compounds highly selective for SGLT1 over SGLT2 (Shibazaki et al., 2012; Fushimi et al., 2013; Dobbins et al., 2015). In preclinical studies, blood glucose excursions were lower after a glucose challenge delivered immediately following a single oral dose of each compound (Ikumi et al., 2008; Sakuma et al., 2010; Shibazaki et al., 2012; Fushimi et al., 2013; Dobbins et al., 2015), and in the only chronic study (Fushimi et al., 2013), KGA-2727-treated STZ-diabetic rats showed lower fed and fasted blood glucose, lower glycated hemoglobin, and higher portal GLP-1 levels; these results are consistent with our LX2761 data. However, none of these preclinical studies 
presented pharmacokinetic or pharmacodynamic data that explored the duration of compound action beyond 4 hours; in the chronic study, compound was delivered as a dietary admixture; this precluded understanding the daily dosing regimen required to improve glycemic control long-term, in contrast to data presented here which clearly showed the longterm glycemic benefits of single daily LX2761 doses. Further, diarrhea is only mentioned briefly in one study (Shibazaki et al., 2012); strategies for dealing with this on-target side effect were not explored in those studies as they were here for LX2761. In the only clinical trial (Dobbins et al., 2015), GSK1614235 given as a single $20-\mathrm{mg}$ dose lowered peak postprandial glucose and raised postprandial GLP-1 levels in healthy humans, with 4 of 12 subjects reporting mild or moderate diarrhea; this study did not include data on single or multiple ascending doses, or the effect of strategies designed to minimize diarrhea in humans.

Data presented here showed that single daily doses of LX2761 improve glycemic control in STZ-diabetic mice in long-term studies. Additional studies in mice and rats identified LX2761 doses that decreased postprandial glucose excursions without causing diarrhea. These data, and data from dose escalation and RS4 pretreatment studies, suggest that clinical trials are warranted to determine if LX2761 doses and dosing strategies exist that provide improved glycemic control combined with adequate gastrointestinal tolerability to people who live with diabetes.

\section{Acknowledgments}

The authors wish to thank Kristi Boehm ELS for her help in preparing the figures and tables, Ryan B. Vance for his help in performing the pharmacokinetic studies, and Arthur Sands for his enthusiastic support of this project. This work was presented in part at the American Diabetes Association 73rd Scientific Sessions, June 21-25, 2013 in Chicago, IL.

\section{Authorship Contributions}

Participated in research design: Powell, Smith, DaCosta, Carson, Goodwin, Harrison, Rawlins, Strobel, Gopinathan, Wilson, Mseeh, Zambrowicz, Ding, Thompson.

Conducted experiments: Smith, Doree, Harris, Greer, DaCosta, Thompson, Jeter-Jones, Gopinathan, Mseeh, Xiong.

Contributed new reagents or analytical tools: Goodwin, Harrison, Strobel, Rawlins.

Performed data analysis: Powell, Smith, Doree, Harris, DaCosta, Thompson, Jeter-Jones, Gopinathan, Wilson, Ding, Xiong.

Wrote or contributed to the writing of the manuscript: Powell, Gopinathan, Wilson, Mseeh, Ding.

\section{References}

Abbott CR, Monteiro M, Small CJ, Sajedi A, Smith KL, Parkinson JR, Ghatei MA and Bloom SR (2005) The inhibitory effects of peripheral administration of peptide YY(3-36) and glucagon-like peptide-1 on food intake are attenuated by ablation of the vagal-brainstem-hypothalamic pathway. Brain Res 1044:127-131.

Al-Tamimi EK, Seib PA, Snyder BS, Haub MD (2010) Consumption of cross-linked resistant starch (RS4(XL)) on glucose and insulin responses in humans. J Nutr Metab DOI: 10.1155/2010/651063.

Balkan B and Li X (2000) Portal GLP-1 administration in rats augments the insulin response to glucose via neuronal mechanisms. Am J Physiol Regul Integr Comp Physiol 279:R1449-R1454.

Bluestone JA, Herold K, and Eisenbarth G (2010) Genetics, pathogenesis and clinical interventions in type 1 diabetes. Nature 464:1293-1300.

Burant CF, Flink S, DePaoli AM, Chen J, Lee WS, Hediger MA, Buse JB, and Chang EB (1994) Small intestine hexose transport in experimental diabetes. Increased transporter mRNA and protein expression in enterocytes. $J$ Clin Invest 93: $578-585$

Carson KG, Goodwin NC, Harrison BA, Rawlins DB, Strobel ES, Zambrowicz B (2014) inventors, Lexicon Pharmaceuticals, Inc., assignee. Preparation of glycosides as antidiabetic inhibitors of SGLT1. U.S. patent PCT/US2013/070556. 30 May 2014.
Cengiz E, Xing D, Wong JC, Wolfsdorf JI, Haymond MW, Rewers A, Shanmugham S, Tamborlane WV, Willi SM, Seiple DL, et al.; T1D Exchange Clinic Network (2013) Severe hypoglycemia and diabetic ketoacidosis among youth with type 1 diabetes in the T1D Exchange clinic registry. Pediatr Diabetes 14:447-454

Centers for Disease Control and Prevention (2014) National Diabetes Statistics Report: Estimates of Diabetes and Its Burden in the United States, US Department of Health and Human Services, Atlanta, GA.

Chen J, Williams S, Ho S, Loraine H, Hagan D, Whaley JM, and Feder JN (2010) Quantitative PCR tissue expression profiling of the human SGLT2 gene and related family members. Diabetes Ther 1:57-92.

Danaei G, Lu Y, Singh GM, Carnahan E, Stevens GA, et al.; Global Burden of Metabolic Risk Factors for Chronic Diseases Collaboration (2014) Cardiovascular disease, chronic kidney disease, and diabetes mortality burden of cardiometabolic risk factors from 1980 to 2010: a comparative risk assessment. Lancet Diabetes Endocrinol 2:634-647.

Debnam ES, Smith MW, Sharp PA, Srai SK, Turvey A, and Keable SJ (1995) The effects of streptozotocin diabetes on sodium-glucose transporter (SGLT1) expression and function in rat jejunal and ileal villus-attached enterocytes. Pflugers Arch 430:151-159.

Defronzo RA (2009) Banting Lecture. From the triumvirate to the ominous octet: a new paradigm for the treatment of type 2 diabetes mellitus. Diabetes 58:773-795. Dobbins RL, Greenway FL, Chen L, Liu Y, Breed SL, Andrews SM, Wald JA, Walker A, and Smith CD (2015) Selective sodium-dependent glucose transporter 1 inhibitors block glucose absorption and impair glucose-dependent insulinotropic peptide release. Am J Physiol Gastrointest Liver Physiol 308:G946-G954.

Dyer J, Wood IS, Palejwala A, Ellis A, and Shirazi-Beechey SP (2002) Expression of monosaccharide transporters in intestine of diabetic humans. Am J Physiol Gastrointest Liver Physiol 282:G241-G248.

Esposito K, Chiodini P, Bellastella G, Maiorino MI, and Giugliano D (2012) Proportion of patients at $\mathrm{HbA} 1 \mathrm{c}$ target $<7 \%$ with eight classes of antidiabetic drugs in type 2 diabetes: systematic review of 218 randomized controlled trials with 78945 patients. Diabetes Obes Metab 14:228-233.

Fushimi N, Teranishi H, Shimizu K, Yonekubo S, Ohno K, Miyagi T, Itoh F, Shibazaki T, Tomae M, Ishikawa-Takemura Y, et al. (2013) Design, synthesis, and structure-activity relationships of a series of 4-benzyl-5-isopropyl-1H-pyrazol-3-yl $\beta$-D-glycopyranosides substituted with novel hydrophilic groups as highly potent inhibitors of sodium glucose co-transporter 1 (SGLT1). Bioorg Med Chem 21: 748-765.

Goodwin NC, Ding Z-M, Harrison BA, Strobel ED, Harris AL, Smith M, Thompson AY, Xiong W, Mseeh F, Bruce DJ, et al. (2017) Discovery of LX2761, a sodiumdependent glucose cotransporter 1 (SGLT1) inhibitor restricted to the intestinal lumen, for the treatment of diabetes. J Med Chem 60:710-721.

Goodwin NC, Harrison BA, Kimball SD, Mabon R, Rawlins DB (2008) inventors, Lexicon Pharmaceuticals, Inc., assignee. Phlorizin analogs as inhibitors of sodium glucose co-transporter 2. U.S. patent PCT/US2008/055775. 12 September 2008.

Holmes GM, Browning KN, Tong M, Qualls-Creekmore E, and Travagli RA (2009) Vagally mediated effects of glucagon-like peptide 1 : in vitro and in vivo gastric actions. $J$ Physiol 587:4749-4759.

Ikumi Y, Kida T, Sakuma S, Yamashita S, and Akashi M (2008) Polymer-phloridzin conjugates as an anti-diabetic drug that inhibits glucose absorption through the $\mathrm{Na}+$ /glucose cotransporter (SGLT1) in the small intestine. $J$ Control Release 125: $42-49$

Inzucchi SE, Bergenstal RM, Buse JB, Diamant M, Ferrannini E, Nauck M, Peters AL, Tsapas A, Wender R, and Matthews DR (2015) Management of hyperglycemia in type 2 diabetes, 2015: a patient-centered approach: update to a position statement of the American Diabetes Association and the European Association for the Study of Diabetes. Diabetes Care 38:140-149.

Lin HV, Frassetto A, Kowalik, JrEJ, Nawrocki AR, Lu MM, Kosinski JR, Hubert JA Szeto D, Yao X, Forrest G, et al. (2012) Butyrate and propionate protect against diet-induced obesity and regulate gut hormones via free fatty acid receptor 3-independent mechanisms. PLoS One 7:e35240.

Martínez I, Kim J, Duffy PR, Schlegel VL, and Walter J (2010) Resistant starches types 2 and 4 have differential effects on the composition of the fecal microbiota in human subjects. PLoS One 5:e15046.

Mudaliar S, Polidori D, Zambrowicz B, and Henry RR (2015) Sodium-glucose cotransporter inhibitors: effects on renal and intestinal glucose transport: from bench to bedside. Diabetes Care 38:2344-2353.

Plamboeck A, Veedfald S, Deacon CF, Hartmann B, Wettergren A, Svendsen LB, Meisner S, Hovendal C, Vilsbøll T, Knop FK, et al. (2013) The effect of exogenous GLP-1 on food intake is lost in male truncally vagotomized subjects with pyloroplasty. Am J Physiol Gastrointest Liver Physiol 304:G1117-G1127.

Powell DR, DaCosta CM, Gay J, Ding Z-M, Smith M, Greer J, Doree D, Jeter-Jones S, Mseeh F, Rodriguez LA, et al. (2013a) Improved glycemic control in mice lacking Sglt1 and Sglt2. Am J Physiol Endocrinol Metab 304:E117-E130.

Powell DR, DaCosta CM, Smith M, Doree D, Harris A, Buhring L, Heydorn W, Nouraldeen A, Xiong W, Yalamanchili P, et al. (2014) Effect of LX4211 on glucose homeostasis and body composition in preclinical models. J Pharmacol Exp Ther 350:232-242

Powell DR, Doree D, Jeter-Jones S, Ding Z-M, Zambrowicz B, and Sands A (2015) Sotagliflozin improves glycemic control in nonobese diabetes-prone mice with type 1 diabetes. Diabetes Metab Syndr Obes 8:121-127.

Powell DR, Smith M, Greer J, Harris A, Zhao S, DaCosta C, Mseeh F, Shadoan MK, Sands A, and Zambrowicz B, and Ding ZM (2013b) LX4211 increases serum glucogon-like peptide 1 and peptide YY levels by reducing sodium/glucose cotransporter 1 (SGLT-1)-mediated absorption of intestinal glucose. J Pharmacol Exp Ther 345:250-259.

Rosenstock J, Cefalu WT, Lapuerta P, Zambrowicz B, Ogbaa I, Banks P, and Sands A (2015) Greater dose-ranging effects on A1C levels than on glucosuria with LX4211, a dual inhibitor of SGLT1 and SGLT2, in patients with type 2 diabetes on metformin monotherapy. Diabetes Care 38:431-438. 
Sakuma S, Teraoka Y, Sagawa T, Masaoka Y, Kataoka M, Yamashita S, Shirasaka Y, Tamai I, Ikumi Y, Kida T, et al. (2010) Carboxyl group-terminated polyamidoamine dendrimers bearing glucosides inhibit intestinal hexose transporter-mediated D-glucose uptake. Eur J Pharm Biopharm 75:366-374.

Sands AT, Zambrowicz BP, Rosenstock J, Lapuerta P, Bode BW, Garg SK, Buse JB Banks P, Heptulla R, Rendell M, et al. (2015) Sotagliflozin, a dual SGLT1 and SGLT2 inhibitor, as adjunct therapy to insulin in type 1 diabetes. Diabetes Care 38 1181-1188.

Shibazaki T, Tomae M, Ishikawa-Takemura Y, Fushimi N, Itoh F, Yamada M, and Isaji M (2012) KGA-2727, a novel selective inhibitor of a high-affinity sodium glucose cotransporter (SGLT1), exhibits antidiabetic efficacy in rodent models. J Pharmacol Exp Ther 342:288-296.

Tolhurst G, Heffron H, Lam YS, Parker HE, Habib AM, Diakogiannaki E, Cameron J, Grosse J, Reimann F, and Gribble FM (2012) Short-chain fatty acids stimulate glucagon-like peptide-1 secretion via the G-protein-coupled receptor FFAR2. Diabetes 61:364-371.

Topping DL, Fukushima M, and Bird AR (2003) Resistant starch as a prebiotic and synbiotic: state of the art. Proc Nutr Soc 62:171-176.

Upadhyaya B, McCormack L, Fardin-Kia AR, Juenemann R, Nichenametla S, Clapper J, Specker B, and Dey M (2016) Impact of dietary resistant starch type 4 on human gut microbiota and immunometabolic functions. Sci Rep 6:28797.

van de Laar FA, Lucassen PL, Akkermans RP, van de Lisdonk EH, Rutten GEHM, and van Weel C (2005) Alpha-glucosidase inhibitors for patients with type 2 diabetes: results from a Cochrane systematic review and meta-analysis. Diabetes Care 28:154-163.

Wajchenberg BL, Feitosa AC, Rassi N, Lerário AC, and Betti RT (2008) Glycemia and cardiovascular disease in type 1 diabetes mellitus. Endocr Pract 14: 912-923.

Weinstock RS, Xing D, Maahs DM, Michels A, Rickels MR, Peters AL, Bergenstal RM, Harris B, Dubose SN, and Miller KM, and Beck RW; T1D Exchange Clinic Network (2013) Severe hypoglycemia and diabetic ketoacidosis in adults with type 1 diabetes: results from the T1D Exchange clinic registry. J Clin Endocrinol Metab 98:3411-3419.
Wright EM, Loo DD, and Hirayama BA (2011) Biology of human sodium glucose transporters. Physiol Rev 91:733-794.

Xin B and Wang H (2011) Multiple sequence variations in SLC5A1 gene are associated with glucose-galactose malabsorption in a large cohort of Old Order Amish. Clin Genet 79:86-91.

Zambrowicz B, Freiman J, Brown PM, Frazier KS, Turnage A, Bronner J, Ruff D, Shadoan M, Banks P, Mseeh F, et al. (2012) LX4211, a dual SGLT1/SGLT2 inhibitor, improved glycemic control in patients with type 2 diabetes in a randomized, placebo-controlled trial. Clin Pharmacol Ther 92:158-169.

Zambrowicz B, Ding Z-M, Ogbaa I, Frazier K, Banks P, Turnage A, Freiman J, Smith M, Ruff D Sands A, et al. (2013) Effects of LX4211, a dual SGLT1/SGLT2 inhibitor, plus sitagliptin on postprandial active GLP-1 and glycemic control in type 2 diabetes. Clin Ther 35:273-285.e7.

Zambrowicz B, Lapuerta P, Strumph P, Banks P, Wilson A, Ogbaa I, Sands A and Powell D (2015) LX4211 therapy reduces postprandial glucose levels in patients with type 2 diabetes mellitus and renal impairment despite low urinary glucose excretion. Clin Ther 37:71-82.e12.

Zhou B, Lu Y, Hajifathalian K, Bentham J, Di Cesare M, Danaei G, Bixby H, Cowan MJ, Ali MK, Taddei C, et al.NCD risk factor collaboration (NCD-RisC) (2016 Worldwide trends in diabetes since 1980: a pooled analysis of 751 population-based studies with 4.4 million participants. Lancet 387:1513-1530.

Zhou J, Hegsted M, McCutcheon KL, Keenan MJ, Xi X, Raggio AM, and Martin RJ (2006) Peptide YY and proglucagon mRNA expression patterns and regulation in the gut. Obesity (Silver Spring) 14:683-689.

Zhou J, Martin RJ, Tulley RT, Raggio AM, McCutcheon KL, Shen L, Danna SC, Tripathy S, Hegsted M, and Keenan MJ (2008) Dietary resistant starch upregulates total GLP-1 and PYY in a sustained day-long manner through fermentation in rodents. Am J Physiol Endocrinol Metab 295:E1160-E1166.

Address correspondence to: Dr. David R. Powell, Lexicon Pharmaceuticals, Inc., 8800 Technology Forest Place, The Woodlands, TX 77381. E-mail: dpowell@lexpharma.com 